\title{
A simulation-based approach to assess sensitivity and robustness of fisheries management indicators for the pelagic fishery in the Bay of Biscay
}

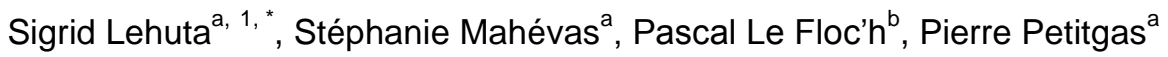 \\ a Laboratoire EMH, IFREMER, BP 21105, 44311 Nantes Cedex 03, France. \\ b UMR AMURE, IUT Quimper, 2, rue de l'université, 29334 Quimper Cedex, France. \\ ${ }^{1}$ Present address: IFREMER, 150 quai Gambetta, B.P. 699, 62321 Boulogne/Mer Cedex, France \\ *: Corresponding author : Sigrid Lehuta, email address : slehuta@ifremer.fr
}

\begin{abstract}
:
Indicators are widely promoted as means to monitor ecosystem status or to evaluate fisheries management performance. "Which indicators are most relevant as decision-support tools in fisheries management?" still remains a topical question. Indicators should be metrics related to fish populations and fleets and should be sensitive to management strategies. However, given the complexity of the processes involved, it is often difficult to unequivocally interpret variations in metrics. A simulation approach was used to study metric properties and to identify robust and relevant fishery indicators. By applying sensitivity analysis methods, simulation designs were built that cross a variety of management scenarios and uncertainty hypotheses. Bio-economic outputs were simulated using a mechanistic model (ISIS-Fish), and their properties were statistically analyzed. This approach was applied to the pelagic fishery of the Bay of Biscay. The analysis of metric properties highlighted the major factors driving variations in each metric and identified the important sources of uncertainty that need to be reduced to allow the use of metrics as indicators. Although very few metrics gave robust indications of management performance, sensitivity indices evidenced how management performances could be improved, and spatially disaggregated metrics provided insights into the mechanisms underlying management performance.
\end{abstract}

\section{Résumé:}

L'utilisation d'indicateurs est largement préconisée pour le suivi et l'évaluation d'impact de stratégies de gestion sur les pêcheries. "Quels indicateurs permettent d'appuyer les décisions de gestion des pêcheries? " reste une question d'actualité. Ces indicateurs doivent être des métriques décrivant populations et flottilles et sensibles aux stratégies de gestion implémentées. Néanmoins, la complexité des mécanismes impliqués, rend l'interprétation des variations d'une métrique souvent ambigüe. Nous proposons une approche par simulation pour étudier les propriétés de métriques et sélectionner des indicateurs de pêcherie pertinents et robustes. En appliquant des méthodes d'analyse de sensibilité, nous avons construit des plans de simulation qui croisent différentes mesures de gestion et sources d'incertitude. Le modèle mécaniste ISIS-Fish est utilisé pour simuler les métriques bioéconomiques dont les propriétés sont ensuite statistiquement analysées. Cette approche est appliquée à la pêcherie pélagique du Golfe de Gascogne. Elle a permis de mettre en évidence les facteurs principaux à l'origine des variations de valeur des métriques et d'identifier les sources d'incertitudes à réduire pour permettre leur utilisation comme indicateurs. Bien que peu de métriques informent de manière robuste sur la performance des mesures testées, les indices de sensibilité fournissent des voies d'amélioration de ces performances et certaines métriques spatialisées améliorent la compréhension des mécanismes induits par les règlementations. 


\section{Introduction}

44
Technical measures, and among them Marine Protected Areas (MPA), are advocated more and more, not only as conservation measures, but also as management tools to help preserve ecosystem structure and quality as well as to enhance fishery yields (Babcock et al. 2005; Pelletier et al. 2005; Field et al. 2006; Stelzenmuller et al. 2007, but see Hart 2006; Sanchirico et al. 2006). Selecting an appropriate spatial management measure to reach ecosystem-management objectives and assessing its performance over time requires keeping track of every component of a system, preferably at high spatial resolution. Many indicators have been proposed in the recent literature as tools to assist with monitoring requirements. Some indicator frameworks have also been proposed which combine indicators and their trends into operational tools (dashboards for instance, Clua et al. 2005) and decision-making supports (Rice and Rochet 2005; Trenkel et al. 2007). These indicators are mostly related to fish communities and populations and intend to reflect fishing impact. On the other hand, indicators related to fishing activity, fleets and economics are seldom considered (but see Piet et al. 2007; Ceriola et al. 2008). However in order to understand management impacts on a fishery, particularly in the case of spatial management measures, spatially explicit bioeconomic indicators of fleet and population dynamics are needed (Pelletier et al. 2008; Pomeroy et al. 2005). Within the pressure-state-response indicator framework (OECD 1993; Garcia and Staples 2000), it requires that fishing is no longer considered solely as a pressure but as a component of the fishery system that responds to the pressure of management. Fishing becomes the manageable link between regulation and biological response to management (Piet et al. 2007). 

something different from what they actually measure (Daan 2005). Within the framework defined above, a metric is considered an indicator of management impact, if, and only if, it is sensitive to management and robust to uncertainties, in other words exclusive. To accurately assess these properties of the metric, the possible causes of variation in the metric value must be disentangled. Empirical data are often not available or are inadequate to perform this type of analysis, thus the relevance of an indicator is often based on conceptual models and experts' judgment. Formal evaluations of robustness to uncertainty are lacking (Fulton et al. 2005). Some authors have proposed the use of simulation in order to study metric properties and their future evolution under various management scenarios (Fulton et al. 2005; Livingston et al. 2005; Travers et al. 2006; Pelletier et al. 2008). This approach requires an operational model to be considered as the "real world". Its outputs are used for metric computations as if they were real world observations. The approach requires that the model be credible, i.e. that it has been validated, and that it provides metrics at a relevant scale. If these requirement are met, the simulation-based approach is the only way to permit replication, particularly regarding environmental conditions, and to allow statistical properties of the metrics to be investigated, for instance by using sensitivity analysis. Additional advantages in comparison to data collection in the field are the perfect knowledge at each time step of the modeled system (i.e. no observation error) and the limited cost of metric computation.

We apply a methodology relying on such a simulation based approach and sensitivity analyses to identify which metrics can be used as fishery management indicators. The goal of the study is twofold: first assessing management measure impacts on a wide range of metrics 


\section{Material and Methods}

\section{Simulation-based approach}

and second identifying indicators, by evaluating the relative sensitivity of the metrics to management measures compared to other sources of variation.

modeled with the ISIS-Fish software; however the methods used here are believed to be transposable to any other case study and model which has been carefully validated. The Bay of Biscay pelagic fishery is a multi-species, seasonal fishery involving French and Spanish fleets (Uriarte et al. 1996). It has suffered a crisis since 2005 when fishing for anchovy, the major target species of the fishery, was banned. The large variability in recruitment is known to affect the sustainability of this fishery (Lehuta et al. 2013) and spatial management measures have been proposed as a complementary tool to quotas to secure the sustainability of the fishery (ICES 1999). Given the multi-species aspect of the fishery, there are concerns that stricter management of anchovy leads to a report of the fishing effort on the other target species of the fishery, sardine, tuna, and sea bass with possible negative impacts on these alternative species. Lehuta et al. (2013) developed a spatial model of the anchovy population and fishery using the ISIS-Fish modeling framework and validated model behavior. Lehuta et al. (2010) tested the impact of a MPA on anchovy biomass and catch. The present study uses an improved version of the model, encompassing the four species and major economic processes, to investigate the effects of various management strategies, including MPAs, on a wide range of ecological and economic metrics representative of the whole fishery.

113 
114 The methodology relies then on 2 steps. Firstly, metrics related to fish populations and 115 fleets, which have been proposed to monitor fishery's dynamics, are reviewed. One or several 116 aggregation levels (area, age-class, time step, and fleet) are associated with each metric. Two 117 categories of metric are distinguished: the first category, referred to as 'management 118 performance indicators' (P), consists of indicators which reflect long term performance of 119 management and reflect management objectives through identified reference points or desired 120 directions. The second category, called 'operational metrics' $(\mathrm{O})$, consists of metrics that 121 could potentially be computed and monitored annually to reflect the status of the fishery but 122

123 Secondly, the operational model is run according to an optimized simulation design, 124 which incorporates multiple uncertainties identified in the system dynamics and the 125 management rules. This allowed for:

126 - first, classical uncertainty analysis to be performed on 'management performance 127 metrics'. This was to assess the ability to reach the management objectives and 128 robustness to uncertainty.

129 - second, sensitivity indices for each metric ('performance' and 'operational') to be 130 computed. These indices are used to extend classical MSE objectives and:

$131 \quad 0$ establish sensitivity and exclusivity of the metrics and their relevance as 132 indicators of management impact

$133 \quad$ identify major sources of variations when performance metrics are not robust

$134 \quad 0$ identify operational metrics which are useful to complete the diagnostic of 135 management impact in particular to understand the reasons for management $136 \quad$ failure to reach objectives 
138 The approach considers that some prerequisites of management strategy evaluation are 139 defined and available. In particular, we need:

140 1) a flexible operational model to simulate the fishery dynamics according to several 141 assumptions of fishery parameterization and several management strategies. In this 142 approach we used the ISIS-Fish model (Pelletier et al. 2009) parameterized and 143 validated for the pelagic fishery in the Bay of Biscay (Lehuta et al., 2013).

144 2) the characterization of gaps in knowledge or uncertainties regarding the Bay of Biscay 145 pelagic fishery which translate into uncertainties in model parameters.

146 3) the list of management strategies with explicit management objectives that should be assessed

150 pelagic fishery (Lehuta et al. 2010; Lehuta et al. 2013). The simulation model is spatially

151 explicit, time discrete (monthly time-step) and enables the modeling of fish populations,

152 fishing activity and management dynamics through three interacting sub-models. The

153 biological model includes a detailed and spatially explicit description of anchovy dynamics,

154 consisting of 15 population stages (larvae to adults), which grow, migrate, reproduce, recruit

155 and die according to stock specific parameters (Lehuta et al. 2013). It is completed with

156 global surplus production models for four populations also targeted by the fleets: sardine

157 (Sardina pilchardus), tuna (Thunnus alalunga), and two populations of sea bass

158 (Dicentrarchus labrax) for the Channel and the Bay of Biscay (Vermard et al. 2012). A

159 fishing behavior model (Random Utility model (RUM)) enables the monthly prediction of the

160 allocation of fishing time on areas and métiers for French fleets based on a combination of

161 fishing habits (historical distribution of fishing time), revenues in the previous time step

162 (month) and a proxy of fuel costs for the activity, computed as the distance to the fishing area 
163 times the price of fuel (Vermard et al. 2008; Vermard et al. 2012). The average pattern of

164 fishing time for the period 2000-2004 is assumed for the Spanish fleet and decision rules are 165 used to reallocate effort depending on management constraints for this fleet (see Management 166 scenarios). Fish prices are dynamically computed as a function of landed volumes (Vermard 167 et al. 2012). Fuel costs are derived from fishing effort, fishing areas and fuel price (Vermard 168 et al. 2012). No technical interactions exist between species because of differences in mesh 169 size and fishermen's ability to recognize species from fish schools.

170 Figure 1 illustrates how the three sub-models interact to compute the distribution of 171 fishing time and derive fishing mortality. At each time step, management rules are updated 172 (catch left to TAC, areas closed, etc) and the métiers impacted by management identified.

173 Combining the updated values of explanatory variables for the RUM and the information on

174 métiers impacted by management, the behavioral model predicts the distribution of the

175 fishing time of each fleet on its possible métiers. The fishing time of a métier applied to a fish

176 population in a zone is proportional to the surface of the métier zone which overlaps the

177 population zone. This fishing time is then standardized between métiers using the catchability

178 parameters of the métiers. Fishing mortality for the population in the zone is finally computed 179 using the accessibility of the population.

180 The model was validated with data of the period 2000-2004 (Lehuta et al. 2013,

181 Vermard et al. 2012). The database of the model can be freely downloaded (Pelagic fishery of 182 the Bay of Biscay, http://www.isis-fish.org/download.html). Model outputs are time series of 183 state variables (biomass, effort, catch, revenues, etc) simulated for each population, fleet and 184 area modeled (Figure 2). 
186

187

188

189

190

191

193

194

195

196

197

\section{Uncertainty hypotheses}

Sensitivity analyses, carried out on the model at various stages of its development (Lehuta 2010; Lehuta et al. 2010; Lehuta et al. 2013), identified parameters which significantly affect model predictions (Table 1): anchovy larval survival, growth and migration rates, accessibility of tuna to fishing, target factors (strength with which a métier targets a species) for sea bass, recruitment of sardine, amount of live bait catches of anchovy by Spanish fleets for tuna fishing (païta), effort level of the fleets, French fleet behavior, species prices and fuel prices. Among those parameters, we distinguish between uncertainty of parameter estimates (the parameter has a constant value but the value is uncertain due to measurement or assessment error) and uncertainty of parameter dynamics (the parameter represents a process prone to inter-annual variability and thus is a variable whose value should change every year but we do not know how). Uncertainty ranges are identified for the former (16 parameters) and alternative scenarios of evolution proposed for the latter.

In this case an exhaustive analysis of possible scenario trajectories through Monte Carlo sampling, as is usually done, was not conceivable given the model computational costs. Instead two contrasting trajectories were designed and their impacts on the results were assessed. For fuel price, assuming a steady value over the simulation period, or alternatively, a linear increase on the basis of the last decade trend can be seen as the two extreme situations possibly encountered in the future. Inter-annual variability in natural mortality and spatial distribution has been demonstrated to be a major driver of fishery dynamics (Lehuta et al. 2013). Due to a lack of information on this inter-annual variability it was not possible to predict most likely scenarios. Instead two contrasting trajectories were compared: $\mathbf{H}_{\mathbf{1}}$, assuming constant values of larval mortality and distribution in spawning areas for the entire simulation; and $\mathbf{H}_{2}$, using the sequence of values of larval mortality and spatial distribution in spawning areas respectively estimated and observed between 2000 and 2009 (Lehuta et al. 
211 2013). In this case, the intention is not to represent the whole range of uncertainty but rather

212 to give indications on how inter-annual variability in parameter values would affect the 213 performance of management. This last factor will enter the uncertainty analysis in a different

214 manner (see Simulation design).

215

\section{Management scenarios and management objectives}

The anchovy fishery was closed from 2005 to 2010 due very low biomass estimates and a long term management plan is currently in development to prevent such a long closure and its dramatic economic consequences in the future. The plan includes provisions for a closure until the end of the management year (which runs from July to June the next year for the anchovy fishery) when estimated current annual biomass is below a threshold fixed at 24000 MT (STECF 2009). This constitutes our base case (scenario 0) and is systematically applied in our simulations. Two kinds of additional measures are proposed, namely Total Allowable Catch (TAC) and Marine Protected Areas (MPAs). The TAC is set mid-year with a harvest rule, "Rule E", defined by the Scientific, Technical and Economic Committee for Fisheries (STECF) and South Western Waters Regional Advisory Council (SWWRAC), establishing the annual TAC level (STECF 2009). Rule E sets a TAC of 7000 MT from July to June the next year for an estimated biomass in June between 24001 MT and the so-called precautionary biomass level (Bpa) of $33000 \mathrm{MT}$. For biomass above Bpa, the TAC is set at a certain proportion $(\gamma)$ of the current biomass level, up to a ceiling of $33000 \mathrm{MT}$, which is the maximum catch level that has been historically recorded (STECF 2009). In our simulations, catch proportion $(\gamma)$ is set at $40 \%$ following the advice of the SWWRAC rather than a rate of $30 \%$ supported by the STECF. According to historical catches, Spain is entitled to $90 \%$ of the TAC. However, a bilateral agreement between Spain and France arranged the transfer of a part of the Spanish quota to France, raising its quota to $40 \%$ of the TAC. 
In addition, MPAs have been proposed since 1999 to help maintain the reproductive

236 potential of the stock (ICES 1999). Here, three designs of MPA are compared. Their

237 objectives are to diminish fishing pressure on juveniles concentrations and on adults during

238 the reproduction: MPA1 consists in the closure of the area located to the west of the Gironde

239 estuary (Figure 3 zone C) during the reproduction (April-August); MPA2 is a closure applied

240 in the same period but concerns the areas off the coast of Landes (Figure 3 zones D and E);

241 finally MPA3 establishes the permanent ban of fishing in the Gironde area taking account of

242 the fact that juveniles concentrate there all year long. Previous studies demonstrated that

243 MPAs alone are unlikely to be effective (Greenstreet et al. 2009; Moustakas et al. 2006).

244 Consequently, in our simulations MPAs are coupled to an effort reduction arbitrarily set to

$24520 \%$. The reaction of French fleets to area closures is dynamically computed by the

246 behavioral model according to the economic and ecological context (Vermard et al, 2012).

247 When the closure of the Landes area (MPA 2) is enforced, it is assumed that the Spanish fleet

248 reallocates its effort on anchovy in the rest of the métier zone still opened to fishing. No

249 decision is required when closing Gironde (MPA1, MPA3) since the Spanish fleet does not

250 fish anchovy in this area. MPAs are either combined with Rule E (scenario 2, 3, 4) or not

251 (scenario 5, 6, 7) which results in eight management strategies including the base case (Table 252 2).

253 To assess the long-term performance of management scenarios, simulations are run

254 for ten years from 2008 onward.

\section{Management performance metrics $(P)$ and Operational metrics $(O)$}

256 Management objectives for the pelagic fishery are gathered from the anchovy long-

257 term plan proposal (STECF 2009) and the requirements for the Good Ecological Status

258 (GES) of exploited fish populations as defined in the Marine Strategy Framework Directive

259 (Cardoso et al. 2010). The qualitative objectives are to secure relatively high yields from 
260 exploitation of the anchovy stock and guaranteeing the stability of the fishery while 261 maintaining a low risk of stock collapse (STECF 2009). Performance metrics $\left(\mathrm{P}_{1}\right.$ to $\left.\mathrm{P}_{6}\right)$ with 262 corresponding reference points (targets or limits) or directions are derived from those 263 management objectives:

$264-\mathrm{P}_{1}$ : Number of years when biomass is above $\mathrm{B}_{\lim }(21000 \mathrm{MT}) . \mathrm{P}_{1}$ must be equal to the 265 number of years of simulation.

$266-\mathrm{P}_{2}$ : Number of years of fishery opening. $\mathrm{P}_{2}$ must be above $90 \%$ of simulation duration $(10 \%$

267 frequency of closure).

$268-\mathrm{P}_{3}$ : Number of years with catch of anchovy higher than 7000 MT which is the threshold of

269 economic profitability expressed by the sector (SWRAC 2008). $\mathrm{P}_{3}$ must be equal to the

270 number of years of simulation.

$271-\mathrm{P}_{4}$ : linear trend in $\mathrm{SSB} . \mathrm{P}_{4}$ should show no degradation to guarantee reproductive capacity, 272 and should thus be positive or null.

$273-\mathrm{P}_{5}$ : Inter-annual variability (expressed by the normalized standard deviation) in landings. $\mathrm{P}_{5}$

274 should be as close to zero as possible as a proxy of fishery stability, to guarantee continuous 275 supply to the industry.

$276-\mathrm{P}_{6}$ : Inter-annual variability in the proportion of the total population represented by recruits

277 (expressed by the normalized standard deviation). The health of the stock has been defined 278 as being proportional to the numbers of larger, older fish (Cardoso et al. 2010). For a short-

279 lived species such as anchovy, however, age structure mainly reflects recruitment success and 280 neither a reference point nor a reference direction exist. We thus considered stability of this 281 structure as positive for population health and recorded the standard deviation of the 282 proportion of recruits in the population, with a low variability being preferable for stock 283 health. 
We expect management measures to have significant benefits and to take the fishery closer to these objectives in comparison to the base case simulation. The values of the indicators are thus also compared with the values obtained in the base case simulation.

The primary objective of analyzing metrics other than performance metrics is to complete the diagnostic with metrics which reflect the effect of management on other features of the target population (such as spatial structure), as well as on the other populations involved in the fishery and on the activity and profitability of fleets. It also aims at identifying relevant indicators of management impact on fishery dynamics that are currently not used. impact was identified from the literature. Among the metrics listed by Lehuta (2010 (Annex1)), those which are computable by the model are sorted and computed at several spatial and temporal scales:, for each of the five populations; for each life stage or age group for anchovy; by country; and by fleet (Tables 3 to 8 ). Given that there was neither a behavioral model nor economic information on Spanish fleets, economic metrics relate only to French fleets. In some cases, management is expected to influence the metrics in a given direction. When documented those expected effects are indicated in tables 3 to 8 . monthly values (species prices $\mathrm{O}_{47-50}$, revenues $\mathrm{O}_{35-38}$ ) or at a particular month (spatial

304 distribution of anchovy in spawning areas $\mathrm{O}_{7}$, proportion of juveniles in the population $\mathrm{O}_{2}$ ).

305 Biomass and spawning intensity per area as well as effort per métier are multidimensional 306 metrics that are transformed into uni-dimensional metrics using a PCA (table 3 and 5, $\mathrm{O}_{7,8,22-}$

307 26). The first axis of PCA and possibly the second when it represented a large amount of 308 variability were used as metrics and the correlation of axis with descriptors guided the 
309 interpretation of these composite metrics. Temporal trends in the annual values of the metrics

310 are searched through linear and log-linear model adjustment $\left(\mathrm{O}_{14-17,39-42,55-58,63-66}\right)$. Non-

311 significant slopes were set to zero. Standard deviation in the time series (de-trended time

312 series when a trend was identified) expresses the annual variability/stability of the metric

313 value $\left(\mathrm{O}_{1,18-21,43-46,49,50)}\right.$.

315 Simulation design and investigation of metric properties

316 The objectives of the paper are twofold: Firstly we carry out a classical management 317 strategy evaluation based on the set of "performance" metrics and accounting for 318 uncertainties. Secondly we propose to explore the sensitivity and robustness properties of 319 performance and operational metrics by computing the sensitivity indices associated with 320 uncertainties and management measures. Both objectives require building and running the 321 simulations according to a statistical simulation design, which includes both management 322 rules and uncertainty sources as factors to allow a comparison of their respective effects and 323 their interactions on the metrics. For a given simulation, a set of values for the uncertain 324 parameters and a management strategy are selected. The simulation design was built 325 sequentially. Firstly, a factorial fractional design (FFD) of resolution V is created for 326 uncertainty sources. It is an optimized design appropriate to compute sensitivity indices for 327 the factors and their first order interactions based on a model of variance decomposition (Box 328 et al. 2005). It consists of an algebraically chosen subset (fraction) of a full factorial design 329 (the full factorial design allows for the estimation of interactions at all orders). In such a 330 design, each factor can take a discrete number of values (modalities), which we chose equal 331 to 2, assuming a linear relationship between factors and outputs. We defined the modalities as 332 being either the extreme values of the uncertainty range or alternative hypotheses on their 333 inter-annual variations (Table 1). The fractional design concerns 17 parameters (256 
334 simulations). Second, to allow for comparison between management measures and between

335 hypotheses $\mathrm{H} 1 / \mathrm{H} 2$ of larval mortality and spatial distribution in the uncertainty analysis, this 336 design was replicated for each of the two hypotheses $\mathrm{H} 1$ and $\mathrm{H} 2$ and each of the eight 337 management scenarios $(256 * 2 * 8=4096$ simulations $)$.

338 the average values of the six performance metrics across management scenarios using radar 341 plots (Garcia and Staples 2000). To allow for an easier reading of the plot, the outer end of the radials represent the management objective $\left(\mathrm{P}_{1}\right.$ to $\left.\mathrm{P}_{3}\right)$ or the desirable direction $\left(\mathrm{P}_{4}\right.$ to $\left.\mathrm{P}_{6}\right)$.

The sensitivity of performance $(\mathrm{P})$ and operational metrics $(\mathrm{O})$ to management measures and their robustness to uncertainty are then investigated. Firstly the values of performance and operational metrics are compared across scenarios using boxplots showing the median and $0.25 / 0.75$ quartiles. The hypothesis tested is $\mathrm{M}_{\mathrm{sc} .}=\mathrm{M}_{0}$ where $\mathrm{M}_{\mathrm{sc}}$. denotes the average value of the metric in simulations with management scenario sc, $s c \in[1,7]$ and $\mathrm{M}_{0}$ is

349 the value of the metric in the base case scenario. The significance of the effect of one 350 scenario compared to another is also evaluated $\left(\mathrm{M}_{\mathrm{sc.} . \mathrm{i}}=\mathrm{M}_{\mathrm{sc} . \mathrm{j}}\right.$, with $\left.\mathrm{i} \neq \mathrm{j}\right)$. The direction and 351 significance of the effect of each management scenario compared to the base case is reported 352 in tables 3 to 8 for each operational metric. An ANOVA is then performed with management scenarios and uncertain parameters as explanatory variables. The results of the ANOVA are used to compute sensitivity indices for the metric and to identify the major sources of variation (Saltelli et al. 2000). 
358 The results are first examined to evaluate management strategies. Performance 359 metrics display different responses to the management scenarios (Figure 4). In terms of 360 management objectives, only metric $\mathrm{P}_{1}$ and $\mathrm{P}_{4}$ show average values close to or above the 361 objective (i.e. anchovy biomass above $\mathrm{B}_{\lim }$ more than 7 years for $\mathrm{P}_{1}$ and positive values for $\left.362 \mathrm{P}_{4}\right) . \mathrm{P}_{2}$, the number of open fishery years, averages around 7 in scenarios with TAC and 363 around 5 in scenarios with only MPAs and for the base case; thus in these last cases, the 364 fishery is closed half the time. Finally, anchovy catches, $\mathrm{P}_{3}$, exceed the economic threshold 365 on average only twice in 10 years with a maximum of three years in the base case. If the 366 performances are globally low, particularly from an economic point of view, some scenarios 367 perform better than others and, with the exception of metric $\mathrm{P}_{3}$, there is good consistency in 368 the ranking of scenarios across performance metrics. These results demonstrate that 369 scenarios coupling TAC with MPA1 or MPA3 are the most efficient and that the base case is 370 the least efficient. The ranking is completely inverted for metric $\mathrm{P}_{3}$ which represents an 371 economic objective. $\mathrm{P}_{1}, \mathrm{P}_{2}$ and $\mathrm{P}_{3}$ values, which represent final outcomes, are not sensitive to 372 the MPA design and the metrics mostly reflect the presence or absence of a TAC. $\mathrm{P}_{4}$ and $\mathrm{P}_{5}$ 373 however, which represent measures of the stability of the fishery over the period, show 374 variations depending on the MPA design. MPA1 and MPA3 generally have a stabilizing 375 effect on the fishery in comparison with MPA2. The variability of population structure $\mathrm{P}_{6}$ 376 averages around $29 \%$ of annual variation and is not influenced by management strategies.

The robustness of the evaluation of management performance to uncertainties is assessed using boxplots (Figure 5). The results must not be interpreted in terms of risk,

380 because they only include extreme values of parameters (assuming uniform distribution and 381 linear response) and two scenarios for inter-annual variability. They still provide information 382 on the range of possible values resulting from the combination of uncertainties. Most metrics 
383 show very large uncertainty intervals, and significant effects of management can only be 384 detected on metrics $\mathrm{P}_{1}, \mathrm{P}_{2}, \mathrm{P}_{4}$ and $\mathrm{P}_{5}$. Even in the worst simulations, scenario 4 remains the 385 most efficient of the considered scenarios and limits negative impacts on the population $386\left(\mathrm{P}_{1}=7, \mathrm{P}_{4}=-4 \%\right)$. On the other hand, none of the scenarios can prevent severe negative 387 economic impacts $\left(\mathrm{P}_{3}=0\right.$ and $\left.\mathrm{P}_{5}=111 \%\right)$. Comparing the two scenarios of inter-annual 388 variability $\mathrm{H} 1 / \mathrm{H} 2$, we demonstrate that $\mathrm{H} 2$ (variable larvae survival and migrations) always

389 results in more pessimistic predictions (Figure 5). However, the ranking of management 390 strategies is unchanged, and thus still supports decision-making and choices between 391 management strategies.

Sensitivity indices permit further explanation of the limited effects of management by breaking down the uncertainty reflected by the boxplots. They indicate the primary source of variation that metrics are responding to (Table 9, Figure 6). As expected performance metrics related to the stability of the population, such as $\mathrm{P}_{6}$ and $\mathrm{P}_{4}$, are more sensitive to interannual variability in anchovy life history traits than to management measures (Figure 5, Table 9). $P_{1}$ is primarily influenced by the hypotheses regarding inter-annual variability and secondarily by management measures. This demonstrates that an appropriate management strategy can help counter the negative effects of unfavorable or unstable environmental conditions (Table 9). The other performance metrics are sensitive to management and 402 parameters related to fishing activity such as effort and amount of anchovy bait fished (païta) $403\left(\mathrm{P}_{2}, \mathrm{P}_{3}, \mathrm{P}_{5}\right)$ (Table 9). $\mathrm{P}_{5}$ responds strongly to management measures and interactions with 404 other parameters such as effort (effp1), anchovy bait catch (paita) and price (spPrice) are significant (Figure 6). It reveals that the effect of management strategies could be amplified or attenuated depending on the values for those parameters. 
Among the 66 metrics investigated, only 9 are primarily sensitive to management: the

409

410

411

412

413

414

415

416

417

418

419

420

421

422

423

424

425

426

427

428

429

430

431

432

percentage of immature anchovy in the catch $\left(\mathrm{O}_{6}\right)$, the final biomasses of tuna $\left(\mathrm{O}_{11}\right)$ and sea bass $\left(\mathrm{O}_{12}, \mathrm{O}_{13}\right)$, the metrics describing effort distribution among métiers for trawlers profill

$\left(\mathrm{O}_{22}, \mathrm{O}_{23}\right)$ and purse seiners from the Basque Country $\left(\mathrm{O}_{26}\right)$, total anchovy landings $\left(\mathrm{O}_{28}\right)$ and Spanish landings $\left(\mathrm{O}_{30}\right)$. Metrics relating to anchovy population mainly reflect inter-annual variability in larval survival and migrations (Table 3). Economic variables like revenues and fuel dependency are highly uncertain and dependent on assumptions on effort, species prices and fuel price evolution; the effect of management is comparatively low (Tables 6, 7, 8).

On the contrary, management decisions influence the 9 variables listed above regardless of environmental or economic forcing and thus they are reliable indicators of management measures impact. In addition, analysis of these variables can help to provide insights into the mechanisms underlying management performance.

Management scenarios in particular are the most influential drivers of effort distribution for the trawler fleet Profile 1 (most dependent on anchovy). This effort distribution is represented by metrics $\mathrm{O}_{22}$ and $\mathrm{O}_{23}$ which are the first and second axes of the PCA on effort per métier. They represent respectively the proportion of total effort spent on métiers targeting anchovy relative to other species and the proportion of effort spent on anchovy in the Gironde area relative to other zones. The metric $\mathrm{O}_{22}$ shows that MPA scenarios $(5,6$, and 7$)$ do not modify the amount of effort on anchovy métiers compared to the base case, while scenarios involving $\operatorname{TAC}(1,2,3,4)$ decrease this effort significantly (Figure 7A). Sensitivity indices (Figure 7B and 7D) confirm the significant effect of scenarios $1,2,3,4$ on the value of $\mathrm{O}_{22}$ as well as the influence of the global level of effort on the metric. They also show that species prices influence the choice of the target species in scenarios involving TAC (interaction effp1:TAC-MPA2, effp1:TAC-MPA2, etc.). Metric $\mathrm{O}_{23}$ shows that in every scenario, the effort is spatially displaced when compared to the base case, 
433 with a reduction of effort in the Gironde area which was the goal of MPA designs 1 and 3

434 (Figure 7C). $\mathrm{O}_{23}$ is mostly sensitive to scenario 7 (MPA3) which significantly reduces the 435 effort in Gironde and secondarily to scenarios 1 (TAC) and 4 (TAC coupled with MPA3).

436 However, sensitivity indices show that the amplitude of this effect is dependent on species 437 price (interactions priceSp:TAC, priceSp:MPA3).

438 These metrics enable an explanation of the relative failure of MPAs according to the 439 performance metrics. Firstly, it shows that MPA1 and MPA3 actually reduce effort in the 440 area Gironde. However, with constant global effort, the effort originally exerted there is 441 reported on métiers also targeting anchovy but in other areas, which maintains a high 442 pressure on the stock. On the other hand, TAC, even when not associated with MPAs in the 443 Gironde, reduced effort in this area when compared to the base case (Figure 7C).

444 Furthermore a limiting TAC closes the fishery before the end of the management year, i.e.

445 before the spawning season, when the Gironde area is usually harvested. This explains the 446 relatively minimal performance gain when TACs are coupled with MPAs. In conclusion, 447 these two metrics in combination with species prices and total effort could be monitored or 448 controlled to assess management efficiency.

449 Metrics $\mathrm{O}_{28}, \mathrm{O}_{29}, \mathrm{O}_{30}$ monitor international landings and landings by country over the 450 simulation period. They are mostly sensitive to uncertainty on païta catches (not landed), 451 stressing the importance of better monitoring of this activity to lower the uncertainty around 452 the metrics and to help improve yield. All three metrics are also sensitive to the level of 453 fishing effort in the Spanish fleet and main French fleets, which demonstrate the influence of 454 the competition between fleets on catches (Table 5). Finally management measures also 455 significantly impacts on catch levels $\left(\mathrm{O}_{28}\right)$ and the distribution of catches between France and 456 Spain $\left(\mathrm{O}_{30}\right)$. With the exception of scenario 1 (TAC), the global catch level is lower in the 457 presence of regulation than in the base case (significant difference for scenarios $3,5,6,7$ ). 
458 However metrics by country reveal contrasting situations. Catches of Spanish fleets are

459 systematically higher than in the base case when a TAC is enforced; while catches by French

460 fleets are lower in all scenarios. Actually Spanish quota is rarely reached in simulations,

461 while French quota is always very limiting.

462

The percentage of immature anchovy in the catch $\mathrm{O}_{6}$ has been proposed as an indicator of fishing intensity by Rochet and Trenkel (2003) to monitor the ability of fish to reproduce at least once. We expected to see a reduction of these catch of small anchovies in scenarios involving the protection of the Gironde area in winter and autumn when juveniles are concentrated there. The results show that all of the proposed scenarios, and particularly the scenario involving MPA3, achieve better protection of the juveniles than the base case. This can be related to the previous evidence that all scenarios reduce fishing pressure in the Gironde area, proving the appropriateness of management to achieve this objective. However, although significant, the variation in values is actually very small $(2.5 \%$ of juveniles in catch in the base case, $1 \%$ with scenario 4 ) and it is questionable if such a small difference can explain the improvement in population health highlighted by performance metrics. The sensitivity indices also show that the metric is sensitive to the hypotheses on natural mortality and migration.

Finally management measures designed to protect anchovy also affect tuna and sea bass $\left(\mathrm{O}_{11}, \mathrm{O}_{12}, \mathrm{O}_{13}\right)$ while sardine biomass $\left(\mathrm{O}_{10}\right)$ is mostly influenced by sardine recruitment (Table 4). Tuna and sea bass biomasses are primarily sensitive to the effort deployed by the trawlers. However, they show significant variations with management, more specifically a

481 decrease in final biomass of sea bass with a TAC, and significant increases for both species

482 with all other management measures (Table 4). These results are unexpected as reinforcing 
management constraints on anchovy was assumed to create increased pressure on other target species. Because sensitivity indices showed sensitivity to effort levels, it is thought that the positive effect doesn't come from the MPA itself but rather from the effort reduction associated with MPAs. This diminution of global effort likely compensates for the increased proportion of time spent on the métiers targeting these species.

This metric analysis provides a detailed assessment of the effect of management measures on the fishery both in terms of performance and understanding of underlying mechanisms.

\section{Discussion}

We have designed a framework to assess the properties of fishery metrics and to evaluate their relevance as indicators of management impact. The simulation design allows for the evaluation of the robustness of management actions to uncertainties, both regarding unpredictable future conditions and poorly understood processes. It also allows sensitivity indices to be computed and used to measure sensitivity of the metrics and to conclude on exclusivity. Although the properties of the metrics analyzed here are specific to the case study, the methodology is transferable to other models and ecosystems. For instance, a comparison with the indicators selected through our method for a flatfish fishery would be of great interest. The approach could also be extended to identify indicators of other pressures (environmental conditions, fishing, decision process, etc.) providing an appropriate simulation design. 
507 2010), and the industry through the SWRAC) into metrics to measure the level of

508 achievement of management objectives by the proposed management strategies. For most of

509 the identified management objectives, metrics and goal values (reference points) although not

510 explicitly identified by management institutions, were straightforward (such as P1 to P4

511 which are based on reference points). For the objectives linked to fishery stability (P5 and

512 P6), we chose normalized standard deviations and specified the desirable direction of change

513 as no reference points were available. This step alerted us to the low number of quantitative

514 objectives actually expressed regarding the anchovy fishery. More generally, moving from

515 qualitative objectives to quantitative indicators is a delicate task.

516

517 The use of a process model, explicitly describing the mechanisms, overcomes major 518 issues regarding the accessibility of information for the evaluation of indicator properties. It

519 allows for the consideration of a wide range of metrics: in particular those related to the

520 economic situation of the fleets; anchovy demographics and spatial structure; and the health

521 of the other target species of the fishery, which meets the requirements of an ecosystem

522 approach to fishery (Jennings 2005). For this purpose, the model developed by Lehuta et al.

523 (2010) to evaluate the impact of management on anchovy biomass and catch has been

524 improved by the addition of a fishing behavior model including economic variables, and the

525 dynamics of the other major target species of the fishery. These aspects are usually not

526 considered in management strategy evaluation because they either cannot be simulated by the

527 models or because the data needed are difficult or expensive to collect empirically (as for

528 spatially disaggregated metrics). In particular, an investigation of the impact of management

529 scenarios on economic sustainability of the fleets is rarely done because the economic data

530 are usually inaccessible (often confidential) and it requires explicit modeling of fishers' 
531 behavior (Holland, 2000, Ulrich et al., 2002, Holland, 2003, Kraak et al.,2008 and Bastardie

532 et al., 2010).

533

534 Another difficulty lies in the synthesis of the information provided by such a large

535 number of metrics. Since the model is spatialized and dynamic with a monthly time step,

536 metrics were intrinsically multidimensional and methods to systematically explore the

537 various aggregation levels were looked for. As previously done by Drouineau et al. (2006)

538 we used PCA to summarize spatially disaggregated information, but Shanon-Wiener indices

539 proposed by Marchal et al. (2001) and Partial Least Square regression (Tenenhaus et al. 1995;

540 Lehuta et al. 2010) could also be used. In a context where spatial resolution is higher, Woillez

541 et al. (2009) also proposed several descriptors of fish distribution. These composite indices

542 are however not directly observable and are therefore unsuitable for monitoring.

543 Nevertheless, we confirmed the need for several aggregation levels, previously stressed by

544 Travers et al. (2006), especially when spatial disaggregation is concerned. For instance, we

545 demonstrated the benefit of collecting spatially disaggregated effort data to monitor the

546 impact of spatial and even non-spatial management measures. Indeed, TAC, when

547 constraining, appeared as an "implicitly spatial measure" (Babcock et al. 2005) that provided

548 protection to zones that were exploited at the end of the management year.

549 Regarding temporal aspects, values of the metrics at the end of the simulations were

550 examined as proxies for long-term performance. Time series were also synthesized by linear

551 trends or values cumulated over time (revenues). Several authors promote the use of indicator

552 trends rather than absolute values to smooth the signal and to avoid alerts due to high inter-

553 annual variability (Trenkel et al. 2007). However in our case, trends presented the same

554 sensitivity to inter-annual variability as did point-in-time values.

555 

of management strategies against their objectives, against each other, and the evaluation of their robustness; and ii) the evaluation of the appropriateness of metrics to assess management strategies through the study of sensitivity indices. reached by the strategies implemented. The exception is the growth rate of the population whose average values are positive. The ranking of the management strategies according to their ability to approach management objectives showed the necessary trade-off between biological and economic goals. The results suggested that scenario 2 (TAC combined with an MPA on area Gironde during spawning) is the most efficient regarding all objectives but one (P3). Scenario 1 (TAC), which is the current regulation, was almost as efficient as it maintained reasonable performances on biological objectives (P1: Blim, P4: population growth, P6: age structure stability) but ensured better results on economic objective (P3: catch level). MPAs on the other hand did not perform much better than the base case. of management measures designed for anchovy were highlighted on the population growth rate of sea bass. Despite the poorly described dynamics for this species, simulations clearly show a negative effect of TACs set for anchovy. Sea bass actually represents the most profitable alternative to anchovy and fishers report their effort on it when anchovy quota is exhausted. However those negative effects do not occur if TAC is coupled with MPA and effort reduction. This supports the adoption of scenario 2 rather than scenario 1 . 
Beyond average values, the uncertainty analysis informs on the robustness of the

581

582

583

584

585

586

587

588

589

590

591

592

593

594

595

596

597

601

602

603

604

conclusions to uncertainties. We considered management strategies as factors of the

uncertainty analysis. Thus the comparison between strategies was possible including an

evaluation of the significance of the differences between their average performance values.

The kind of uncertainty analysis we used does not provide results in term of risks for management to fail, because the distribution of uncertain parameters is assumed to be uniform and because $\mathrm{H}_{1} / \mathrm{H}_{2}$ are not an exhaustive representation of uncertainty in mortality and migration. This approach rather brackets uncertainty. Here, confidence intervals reflect extreme consequences of a strategy accounting for a wide range of interacting uncertainty sources. Within a scenario of mortality and migration $\left(\mathrm{H}_{1} / \mathrm{H}_{2}\right)$, it thus corresponds to a strict application of the precautionary approach. Here the uncertainty analysis confirmed that scenario 2 is not only the most efficient but also the most cautious since extreme values obtained stay acceptable regarding objectives. Moreover even if the accuracy of simulated absolute values can be questioned, this approach provides a ranking of management strategies relative to each other, and in our case, showed that this ranking was robust to uncertainty.

metrics and operational metrics and to conclude on the metrics' appropriateness as indicators of management impact.

Sensitivity indices allow for the evaluation of metrics regarding two of the criteria that make them indicators: sensitivity and exclusivity (Rochet and Trenkel 2003). The sensitivity index related to management precisely measures sensitivity in the sense of Rochet and Trenkel (2003), i.e. ability to respond to the pressure under study (in this case management measures). The other sensitivity indices reflect robustness to uncertainties and if negligible, 
605 show the exclusivity of the indicator to management. Regarding performance metrics, we 606 showed that management decisions should rather be based on metrics P1 (frequency above 607 Blim), P2 (frequency of fishery openings), P3 (catch level), P5 (stability of catch), because 608 the advice based on P4 (trend in biomass) and P6 (variability of age structure) largely 609 depends on uncertain processes and future conditions met by the fishery; in other words: P4 610 and P6 do not meet the exclusivity criteria.

611 Furthermore, we identified new metrics sensitive and even exclusive to management, 612 which are useful to understand the changes induced by management implementation.

613 Operational metrics $\left(\mathrm{O}_{6,11-13,22-23,26,28,30,45}\right)$ were sensitive to management and offered insight 614 in the mechanisms underlying management actions. Particularly the study of fishing effort 615 distribution among areas and métiers showed that the considered scenarios, even when they 616 failed to reach management objectives, are actually efficient in reducing the pressure on the

617 Gironde area and in reducing the catch of juvenile anchovy, which were implicit objectives of 618 management. However, when MPAs are not coupled to TACs, the effort is reported on 619 anchovy in other areas rather than on other species, providing an explanation for low benefits 620 of MPAs.

622 If an indicator is more sensitive to an uncertainty source than it is to management 623 actions, it indicates that the value of the indicator cannot be accurately predicted by the model 624 until the uncertainty is reduced. The direction of the impact of management measures on its 625 value may still be evidenced but is unlikely to be significant. Furthermore, significant 626 interactions between management and parameters indicate synergies or antagonisms. This 627 means that the expected impact of management actions on the indicator value may not only 628 be biased but that the direction of the impact could also be the opposite. Consequently, the 629 simulated value of the indicator cannot be trusted. 
630 These significant interactions also warn us about our possible inability to interpret the

631 metric variations measured in the field, if the uncertainty source cannot also be precisely

632 measured.

633 It is important to make a distinction here between different kinds of uncertainty in

634 order to correctly interpret sensitivity indices. We differentiate metrics sensitive to uncertain

635 knowledge from metrics sensitive to uncertain future conditions. In the first case, the

636 sensitivity indices inform on the necessity to improve knowledge to allow robust assessment

637 using the model and correct interpretation of metric values measured on the field. In MSE,

638 uncertainty analyses are often limited to few processes (usually recruitment) and few

639 parameters (catchability, weight at age). Here we evidence the risk of disregarding other

640 uncertainty sources; in particular risk of failure could be underestimated. Population growth

641 rate for instance was influenced by the hypotheses made on the effort of the Spanish fleet and

642 the level of catches for païta that are usually not explicitly accounted for. "Operational

643 metrics" were also mostly sensitive to uncertainty due to lack of knowledge about the fishery

644 because they represent finer processes and more local scales on which knowledge is more

645 uncertain, typically economic processes (prices). The sensitivity analysis thus helps in

646 identifying needs and priorities in data collection.

647 The second case concerns the uncertainty of processes which vary from year to year,

648 possibly under the pressure of environment. In these cases, sensitivity indicates that the

649 impact of the management strategy depends on the conditions met, which are usually

650 unpredictable. This is the case for performance metrics $\mathrm{P}_{4}$ (growth rate) and $\mathrm{P}_{6}$ (inter-annual

651 variability of recruits) and for most of the operational metrics related to anchovy population

652 dynamics, spatial and demographic structure. Shin et al. (2005), Greenstreet and Rogers

653 (2006) and Travers et al. (2006) already pointed out the sensitivity of age structure and

654 metrics related to size to environmental variability. These indicators are typically inadequate 
655 to monitor the impact of management. For instance, it is often considered that high

656 population growth rate $\left(\mathrm{P}_{4}\right)$ is a sign of population health and is implicitly attributed to

657 efficient management. In the case of anchovy, sensitivity indices indicate however that a high

658 population growth rate value most likely results from a combination of favorable

659 environmental and/or economic conditions rather than from efficient management.

660 Conversely no management strategy can overcome adverse conditions. If the relationship

661 between the metrics and the forcing is resolved, it is possible to use the metric in combination

662 with indicators of the current condition of the system. For instance population growth rate

663 could be interpreted in terms of management impact if an index of larval survival was

664 available. Reference points could then be conditioned to the value of the larval survival

665 index. An approach for the identification of reference point and the combination of variables

666 was proposed by Link et al. (2002) using multivariate analysis such as PCA.

667

668

669

Finally we also found that the information provided by sensitivity indices was directly interpretable in proposing new management actions.

670 As previously discussed growth rate was more sensitive to effort level and païta than to the

671 management measures evaluated. Most performance metrics were actually sensitive to these

672 two parameters, which are uncertain but manageable factors. Regulation of effort or control

673 of païta catches thus appear as potentially efficient management actions. This is relevant to

674 ongoing discussions about the necessity to include live bait catches of anchovy in the TAC

675 (SWRAC 2009).

676

677 Acknowledgements 
678 This study was carried out with financial support from the Commission of the European 679 Communities as a contribution to FP6 Specific Targeted Research Project 044168 680 (AFRAME). The authors are grateful to Jean-Pierre Gauchy (INRA) for methodological help 681 on the experimental design development, to Sarah Kraak for precious comments on the form 682 and substance and to Mike Fitzpatrick for helpful editorial comments. Technical support on 683 ISIS-Fish was provided by the programming company Code Lutin. The authors also thank 684 two anonymous reviewers for valued comments which improved the manuscript.

685 


\section{References}

688 Amand, M., Pelletier, D., Ferraris, J., Kulbicki, M. 2004. A step toward the definition of 689 ecological indicators of the impact of fishing on the fish assemblage of the abore reef 690 reserve (new caledonia). Aquat. Living Resour. 17: 139-149.

691 Babcock, R.C., Kelly, S., Shears, N.T., Walker, J.W. and Willis, T.J. 1999. Changes in 692 community structure in temperate marine reserves. Mar. Ecol. Prog. Ser. 189: 125-134.

693 Babcock, E.A., Pikitch, E.K., McAllister, M.K., Apostolaki, P. and Santora, C. 2005. A

694 perspective on the use of spatialized indicators for ecosystem-based fishery management through spatial zoning. ICES Journal of Marine Science 62: 469-476.

Bastardie, F., Nielsen, J.R., Andersen, B.S. and Eigaard, O.R. 2010. Effects of fishing effort

Box, G., Hunter, J.S. and Hunter, W.G. 2005. Statistics for experimenters: design, innovation, and discovery. S.E. Wiley Series in Probability and Statistics.

Cardoso, A.C., Cochrane, S., Doerner, H., Ferreira, J.G., Galgani, G.et al. 2010. Marine strategy framework directive - draft management group report. European commission joint research center - International Council for the exploration of the sea.

Ceriola, L., Accadia, P., Mannini, P., Massa, F., Milone, N.et al 2008. A bio-economic indicators suite for the appraisal of the demersal trawl fishery in the southern adriatic sea (central mediterranean). Fish. Res. 92: 255-267. multidisciplinary indicator dashboards for coral reef fisheries management. Aquat. Living Resour. 18: 199-213. 
710 Daan, N. 2005. An afterthought: ecosystem metrics and pressure indicators. ICES Journal of $711 \quad$ Marine Science 62(3): 612-613.

712 Drouineau, H., Mahévas, S., Pelletier, D. and Beliaeff, B. 2006. Assessing the impact of 713 different management options using isis-fish: the french hake-nephrops mixed fishery 714 of the bay of biscay. Aquatic Living Resource 19: 15-29.

715 Field, J.C., Punt, A.E., Methot, R.D. and Thomson, C.J. 2006. Does mpa mean ‘major 716 problem for assessments'? considering the consequences of place-based management 717 systems. Fish and Fisheries 7: 284-302.

718 Fulton, E., Smith, A. and Punt, A. 2005. Which ecological indicators can robustly detect 719 effects of fishing?. ICES Journal of Marine Science 62(3): 540-551.

720 Garcia, S. and Staples, D. 2000. Sustainability reference systems and indicators for responsible marine capture fisheries : a review of concepts and elements for a set of guidelines. Marine Freshwater Research 51: 385-426.

Greenstreet, S.P. and Rogers, S.I. 2006. Indicators of the health of the north sea fish community: identifying reference levels for an ecosystem approach to management. ICES J. Mar. Sci. 63: 573-593.

Greenstreet, S.P.R., Fraser, H.M. and Piet, G.J. 2009. Using mpas to address regional-scale ecological objectives in the north sea: modelling the effects of fishing effort displacement. ICES J. Mar. Sci. 66: 90-100.

Hart, D.R. 2006. When do marine reserves increase fishery yield?. Canadian Journal of Fisheries and Aquatic Sciences 63: 1445-1449.

731 Holland, D.S. 2000. A bio-economic model of marine sancturaies on gorges bank. Canadian 732 Journal of Fisheries and Aquatic Sciences 57: 1307-1319. 
733 Holland, D.S. 2003. Integrating spatial management measures into traditional fishery

734 management systems: the case of the georges bank multispecies groundfish fishery.

735 ICES Journal of Marine Science 60: 915-929.

736 ICES. 1999. Report of the ICES advisory committee on fishery management. ICES CRR $737 \quad \mathrm{n}^{\circ} 236$.

738 ICES. 2009. WGANSA. Report of the working group on anchovy and sardine. ICES CM 739 2009/ACOM:13.

740 Jennings, S. 2005. Indicators to support an ecosystem approach to fisheries. Fish and $741 \quad$ Fisheries 6: 212-232.

742 Kraak, S.B.M., Buisman, F.C., Dickey-Collas, M., Poos, J.J., Pastoors, M.A.et al. 2008. The 743 effect of management choices on the sustainability and economic performance of a 744 mixed fishery: a simulation study. ICES Journal of Marine Science 65: 697-712.

745 Le Corre, L., Brigaudeau, C., Daurès, F., Le Floc'h, P., Van Iseghem, S. et al. 2010. Les

746 indicateurs économiques à la pêche : analyse comparative des données comptables et 747 d'enquête. UMR Amure, Ifremer-IUEM.

748 Lehuta, S. 2010. Management impact on the pelagic fishery of the bay of Biscay : What is 749 certain? How to describe? PhD Thesis, Agrocampus-ouest. Available from $750 \quad$ http://archimer.ifremer.fr/doc/00025/13630/.

751 Lehuta, S., Mahévas, S., Petitgas, P. and Pelletier, D. 2010. Combining sensitivity and 752 uncertainty analysis to evaluate the impact of management measures with isis-fish:

753 marine protected areas for the bay of biscay anchovy (engraulis encrasicolus) fishery.

$754 \quad$ ICES journal of marine science 67: 1063-1075.

755 Lehuta, S., Petitgas, P., Mahévas, S., Huret, M., Vermard, Y.et al. in press. Selection and 756 validation of a complex fishery model using an uncertainty hierarchy. Fish. Res. 
757 Link, J.S., Brodziak, J.K.T., Edwards, S.F., Overholtz, W.J., Mountain, D.et al 2002. Marine

758 ecosystem assessment in a fisheries management context. Canadian Journal of Fisheries $759 \quad$ and Aquatic Sciences 59: 1429-1440.

760 Livingston, P.A., Aydin, K., Boldt, J., Ianelli, J. and Jurado-Molina, J. 2005. A framework

761 for ecosystem impacts assessment using an indicator approach. ICES Journal of Marine

$762 \quad$ Science 62: 592-597.

763 Marchal, P., Nielsen, J., Hovgard, H. and Lassen, H. 2001. Time changes in fishing power in 764 the danish cod fisheries of the baltic sea. ICES Journal of Marine Science 58: 298-310.

765 Moustakas, A., Silvert, W. and Dimitromanolakis, A. 2006. A spatially explicit learning

766 model of migratory fish and fishers for evaluating closed areas. Ecological Modelling

$767 \quad$ 192: $245-258$.

768 OECD. 1993. OECD core set of indicators for environmental performance reviews. OECD

769 environment monographs no. 83. OECD. Paris. Available from

770 http://www.fao.org/ag/againfo/programmes/en/lead/toolbox/Refer/gd93179.pdf.

771 Pelletier, D., Claudet, J., Ferraris, J., Benedetti-Cecchi, L. and Garcia-Charton, L. 2008.

772 Models and indicators for assessing conservation and fishery-related effects of marine

773 protected areas. Canadian Journal of Fisheries and Aquatic Sciences 65: 1-15.

774 Pelletier, D., Garcia-Charton, J.A., Ferraris, J., David, G., Thébaud, O.et al 2005. Designing

775 indicators for assessing the effects of marine protected areas on coral reef ecosystems: a

776 multidisciplinary standpoint. Aquat. Living Resour. 18: 15-33.

777 Pelletier, D., Mahevas, S., Drouineau, H., Vermard, Y., Thebaud, O.et al 2009. Evaluation of

778 the bioeconomic sustainability of multi-species multi-fleet fisheries under a wide range

779 of policy options using isis-fish. Ecological Modelling 220: 1013 - 1033.

780 Piet, G.J., Quirijns, F.J., Robinson, L. and Greenstreet, S.P.R. 2007. Potential pressure

781 indicators for fishing, and their data requirements. ICES J. Mar. Sci. 64: 110-121. 
782 Pomeroy, R., Watson, L., Parks, J. and Cid, G. 2005. How is your mpa doing ? a

783 methodology for evaluating the management effectiveness of marine protected areas.

$784 \quad$ Ocean \& Coastal Management 48: 485-502.

785 Rice, J. and Rochet, M. 2005. A framework for selecting a suite of indicators for fisheries

786

787

788

789

790

791

792

793

794

795

796

797

798

799

800

801

802

803

804

Rochet, M. and Trenkel, V. 2003. Which community indicators can measure the impact of fishing ? a review and proposals. Canadian Journal of Fisheries and Aquatic Sciences 60: 86-99.

STECF. 2009. Proposal for a council regulation establishing a long-term plan for the anchovy stock in the bay of biscay and the fisheries exploiting that stock. Commission of the european communities.

SWRAC. 2008. Contribution du CCR sud sur le document informel de la commission européenne pour un plan de gestion à long terme de la pêcherie d'anchois du golfe de gascogne. Conseil Consultatif Régional pour les eaux occidentales australes. Available from http://www.ccrs.eu/EN/download.asp?../Upload/EN/Avis/Syntheses/Anchoa_ContribucionCCRSur22 0708_ES_2.pdf

SWRAC. 2009. Bay of biscay anchovy fishery: updated approximate figures for the fleet and fishing effort displacement. SWRAC. Advice 20 -25 November 2009. Available from http://www.ccrs.eu/EN/download.asp?../Upload/EN/Avis/Syntheses/AvisAnchois_251109_EN.pdf

Saltelli, A., Chan, K. and Scott, E.. 2000. Sensitivity analysis. Saltelli A, K.Chan et E.Scott (Eds.). Wiley. 
805 Sanchirico, J.N., Malvadkar, U., Hastings, A. and Wilen, J.E. 2006. When are no-take zones

806 an economically optimal fishery management strategy?. Ecological Applications 16(5):

$807 \quad 1643-1659$.

808 Shin, Y., Rochet, M., Jenning, S., Field, J., Gislason, H. 2005. Using size-based indicators to

809 evaluate the ecosystem effects of fishing. ICES Journal of Marine Science 62: 384-396.

810 Stelzenmuller, V., Maynou, F. and Martin, P. 2007. Spatial assessment of benefits of a

811 coastal mediterranean marine protected area. Biological conservation 136: 571-583.

812 Tenenhaus, M., Gauchy, J.P. and Ménardo, C. 1995. Régression pls et applications. Revue

813 de statistiques appliquées tome 43(1): 7-63.

814 Travers, M., Shin, Y., Shannon, L., Cury, P. 2006. Simulating and testing the sensitivity of

815 ecosystem-based indicators to fishing in the southern benguela ecosystem. Canadian

816 Journal of Fisheries and Aquatic Sciences 67: 943-956.

817 Trenkel, V., Rochet, M., Mesnil, B. 2007. From model-based prescriptive advice to

818 indicator-based interactive advice. ICES Journal of Marine Science 64(4): 768-774.

819 Ulrich, C., Pascoe, S., Sparre, P.J., De Wilde, J. and Marchal, P. 2002. Influence of trends in

820 fishing power on bioeconomics in the north sea flatfish fishery regulated by catches or

821 by effort quotas. Canadian Journal of Fisheries and Aquatic Sciences 59: 829-843.

822 Uriarte, A., Prouzet, P., Villamor, B. 1996. Bay of biscay and ibero atlantic anchovy

823 populations and their fisheries. Sci. Mar. 60 (Suppl. 2): 237-255.

824 Vermard, Y., Marchal, P., Mahevas, S. and Thebaud, O. 2008. A dynamic model of the bay

825 of biscay pelagic fleet simulating fishing trip choice: the response to the closure of the

826 european anchovy (engraulis encrasicolus) fishery in 2005. Canadian Journal of

$827 \quad$ Fisheries and Aquatic Sciences 65: 2444-2453.

828 Vermard Y., Lehuta S., Mahevas S., Thebaud O., Marchal P., Gascuel D. 2012. Combining

829 fleet dynamics and population dynamics for a volatile fishery: the example of the 
830 anchovy fishery of the Bay of Biscay. available from

831 http://archimer.ifremer.fr/doc/00107/21858/.

832 Woillez, M., Rivoirard, J. and Petitgas, P. 2009. Notes on survey-based spatial indicators for 833 monitoring fish populations. Aquat. Living Resour. 22: 155-164.

834 


\section{Figure captions:}

836 Figure 1: Graphical summary of the ISIS-Fish model of the pelagic fishery in the Bay of

837 Biscay. The chart represents the events simulated by each sub-model (biology, exploitation

838 and management) at each time step ( $t$, month) and the connections between them which result

839 in the computation of the fishing mortality $(F)$. Bolded words represent processes; italic is

840 used to indicate state variables dynamically computed. F: Fishing mortality; M: natural

841 mortality; VPUE: Value landed per Unit of Effort.

843 Figure 2: Examples of time series of outputs produced by the ISIS-Fish model of the pelagic

844 fishery in the Bay of Biscay. The average time series obtained in the base case simulation is

845 plotted (continuous bold line) together with 95\% confidence intervals derived from the

846 simulation design. The dash line represents the average time series obtained in simulations

847 with management strategy 2 (TAC +MPA 1). A. Monthly biomass of anchovy, with

848 reference levels Blim (biomass limit) and Bpa (precautionary biomass). B. Monthly effort of

849 trawlers profil 1 on métiers targeting sea bass in the Channel. C. Monthly catches of anchovy

850 by trawlers profil 1 in area Gironde. D. Monthly revenues generated by French fleets.

852 Figure 3: Map of biological and management areas for anchovy in the Bay of Biscay. A

853 North, B. Rochebonne, C. Gironde, D. Landes off, E. Landes coastal.

855 Figure 4: Radar plot of average value obtained in simulation for the performance metrics in 856 each management scenarios. Performance metrics are ordered on the graph according to the 857 dimension to which they referred: biological objectives on the right and economic objectives 858 on the left. Metrics are scaled so that the more on the edge the better. The scale goes from 0 859 to 10 (simulation duration) for $\mathrm{P}_{1}$ to $\mathrm{P}_{3}$, from 0 to the maximum value observed in simulation 860 for $\mathrm{P}_{3}$. We plot the inverse of $\mathrm{P}_{5}$ and $\mathrm{P}_{6}$ so that the values range from Infinity to the lowest 861 value observed in simulation. P1: no. years with biomass higher than $\mathrm{B}_{\lim } \in[0 ; 10]$; P2: no. 862 years of open closure $\in[0 ; 10]$; P3: no. years with anchovy catch $>7000 t \in[0, \max =3.47]$; P4: 863 trend in biomass time series $\in$ [min;max]; P5: 1/inter-annual variation in anchovy landings $\in$ 864 [Infinity;max]; P6: 1/variability of age structure $\in$ [Infinity;min]. "min" and "max" stands 865 respectively for minimum and maximum obtained in simulations.

866 
867 Figure 5: Boxplots of the values of the six performance metrics depending on management 868 strategies (x axis) (boxes represent the median and first and third quartile). The solid square 869 represents the average value obtained in simulations with constant natural mortality and 870 migration scheme, while the open square is the average value in simulations including inter871 annual variability in these processes.

873 Figure 6: Sensitivity indices (16 highest) corresponding to each uncertainty source and 874 management scenario for metric $\mathrm{P}_{4}$ : Anchovy population growth rate and $\mathrm{P}_{5}$ : Variability of 875 anchovy landings. Sensitivity indices relating to management are in black. ":" represents 876 interaction between two factors. Please report to Table 1 for the meaning of the abbreviations.

878 Figure 7: Effect of management scenarios on the allocation of effort of trawlers profile 1 on 879 métiers, metrics $\mathrm{O}_{22}$ (top) and $\mathrm{O}_{23}$ (bottom). A and $\mathrm{C}$ : Simulated values of the metric 880 depending on management scenario ( $\mathrm{x}$ axis) (boxes represent the median and first and third 881 quartile). B and D:. Sensitivity indices (16 highest) of the metric corresponding to each 882 uncertainty source and management scenario and computed based on variance 883 decomposition; “:” represents interaction between two factors. Please report to Table 1 for the 884 meaning of the abbreviations. 
Table 1: The table present the list of uncertain parameters considered in the uncertainty analysis. It describes the role of the parameter in the model in the frst column and the two modalities (alternative values) considered and the rational for their choice with corresponding references in the second column.

\begin{tabular}{|c|c|}
\hline Parameter (abbreviated name) & Description and modalities \\
\hline $\begin{array}{l}\text { Larval survival rate and spatial } \\
\text { distribution of biomass in spawning } \\
\text { areas }(\mathrm{HypH})\end{array}$ & $\begin{array}{l}\text { - Hyp. H1: parameters are kept constant at } \\
\text { the average assessed/observed value on } \\
\text { the period 2000-2009 } \\
\text { - Hyp. H2: sequence of values } \\
\text { assessed/observed on the period 2000- } \\
2009 \\
\text { (Lehuta et al., 2013) }\end{array}$ \\
\hline Anchovy growth curve (gro) & $\begin{array}{l}\text { The uncertainty interval for the } \mathrm{K} \text { parameter of } \\
\text { the Von Bertalanffy growth curve is unknown. } \\
\text { Extreme values for } \mathrm{K} \text { are assessed by hindcast } \\
\text { simulations, assuming that: } \\
\text { - The minimum is the lowest value } \\
\text { allowing the simulated population to } \\
\text { increase without fishing } \\
\text { - The maximum is the highest value, with } \\
\text { which the simulated population decrease } \\
\text { with fishing levels of } 2000-2004\end{array}$ \\
\hline $\begin{array}{l}\text { Accessibility of tuna in autumn } \\
\text { (corresponds to the biological part of } \\
\text { catchability) (Qt) }\end{array}$ & $\begin{array}{l}+/-20 \% \text { of estimated value }\left(6.76 \mathrm{e}^{-5}\right) \text { (Lehuta, } \\
2010)\end{array}$ \\
\hline $\begin{array}{l}\text { Target factors (intensity of search of a } \\
\text { métier on a species) for Channel sea bass } \\
\text { in December-January (Tbc) }\end{array}$ & $\begin{array}{l}\text { Bounds of the confidence intervals of the } \\
\text { estimates (Lehuta, 2010, Annex 3). }\end{array}$ \\
\hline $\begin{array}{l}\text { Target factors (intensity of search of a } \\
\text { métier on a species) for Biscay sea bass in } \\
\text { April-May (Tbb) }\end{array}$ & $\begin{array}{l}\text { Bounds of the confidence intervals of the } \\
\text { estimates (Lehuta, 2010, Annex 3). }\end{array}$ \\
\hline Sardine recruitment (numbers) (Rsar) & $\begin{array}{l}\text { Two alternatives values }\left(3.3 \mathrm{e}^{9} ; 1.6 \mathrm{e}^{9}\right) \\
\text { corresponding to the average five best, and }\end{array}$ \\
\hline
\end{tabular}


respectively worst recruitments observed by acoustic surveys between 2000 and 2009

(ICES, 2009).

Live bait "païta" catches (paita)

- Harvest of 2 MT per month and vessel (A. Uriarte, pers. Comm.)

- No catches at all.

Fishing time per month for each of five Minimum and maximal monthly effort observed fleets between 2000 and 2004 (based on logbook (effp1,effp2,effb1,effb2,effsp) data). (Lehuta et al., 2013)

Weight given to opportunistic vs. Confidence intervals for the Random Utility traditional behavior of French fleets Models estimates relating to profitability and (coefRump1, coefRump2, habits.

coefRumb1, coefRumb2)

(Vermard et al. 2012).

Average annual fuel price (priceGas)

2 hypotheses :

- constant value equal to the fuel price in $2008\left(0.59 € . \mathrm{L}^{-1}\right)$

- $\quad$ same linear trend as from 1996 to 2008 ( $3 \%$ annual increase)

Landings prices of the five populations $+/-20 \%$ variation of the flexibility coefficient. (spPrice) This determines the influence of landed volume on species price.

(Vermard et al. 2012) 
Table 2: Description of the management scenario tested in the study. The first column present to number used in the text to refer to the different scenarios, while the management measures enforced are described in the second column.

Description of the management scenario (combination of management measures)

$\mathbf{0}$ Base case : closure of anchovy fishery when biomass drop below $\mathrm{B}_{\lim }{ }^{\mathrm{a}}=21000 \mathrm{MT}$

1 Base case + rule E: TAC $=7000 \mathrm{MT}$ if $24000 \mathrm{MT}<$ biomass $<33000 \mathrm{MT}$

$$
\mathrm{TAC}=\min (33000 \mathrm{MT}, \gamma \text { biomass }), \gamma=0.4
$$

2 Base case + rule E $+\mathrm{MPA}^{\mathrm{b}} 1$ : Gironde April to August + effort control (20\% reduction)

3 Base case + rule E + MPA2: coast of Landes April to August + effort control (20\% reduction)

4 Base case + rule E + MPA3: Gironde all year round + effort control (20\% reduction)

5 Base case + MPA1 + effort control

6 Base case + MPA2 + effort control

7 Base case + MPA3 + effort control

${ }^{\mathrm{a}} \mathrm{B}_{\text {lim }}$ : Biomass limit

${ }^{\mathrm{b}} \mathrm{MPA}$ : Marine Protected Area 
Table 3: Indicators related to the anchovy population and direction and significance of the effect of management scenarios on their value.

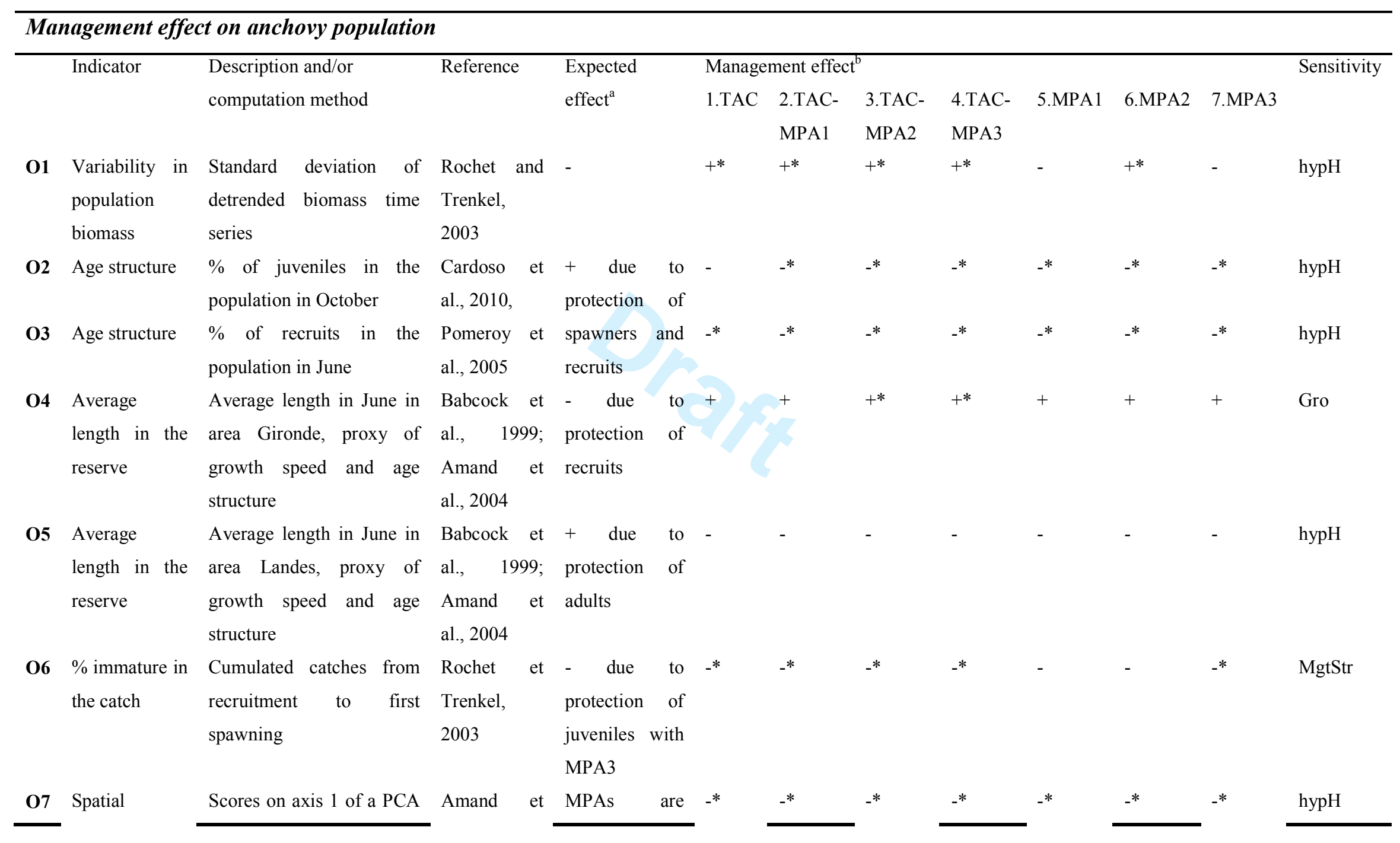




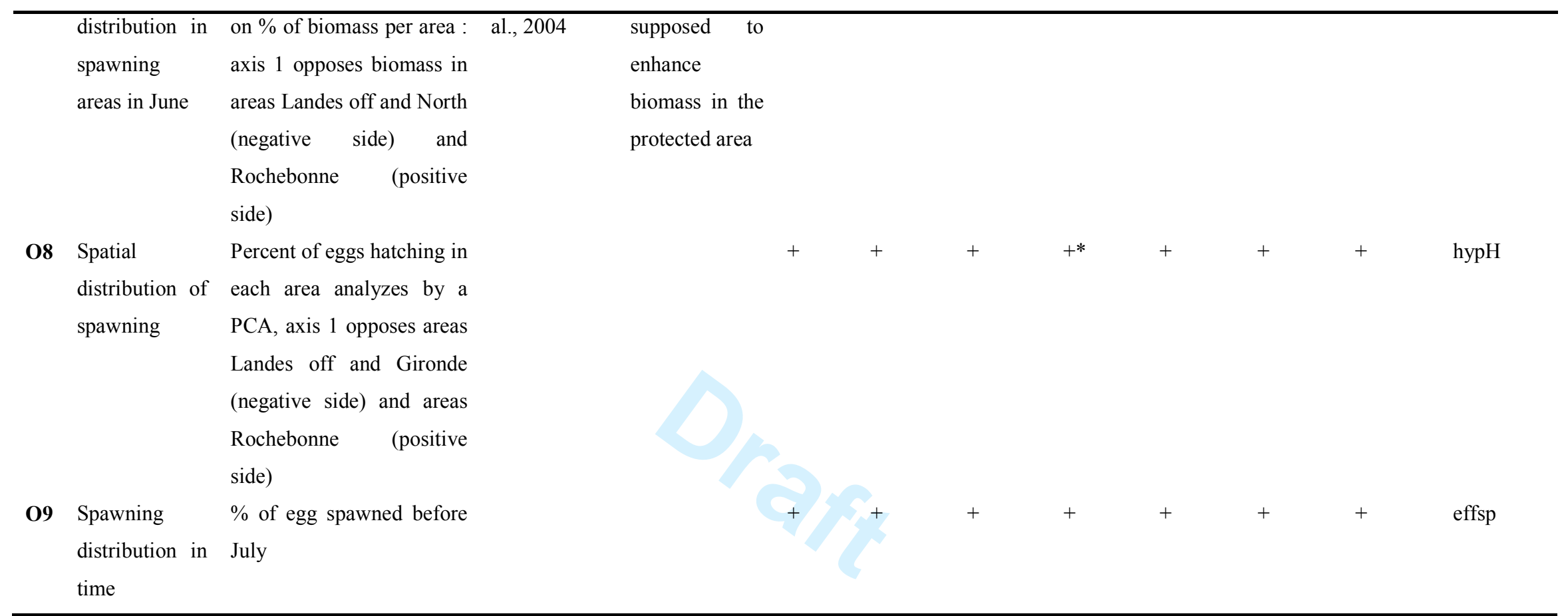

\footnotetext{
${ }^{a}$ When described in the literature, expected direction of change in the value of the metric due to management strategies.

${ }^{b}$ Direction of the effect of each management strategy on the metric compared to the base case (+ positive effect ; - negative effect). '*' indicates significance of the effect (pvalue $<0.05$ ).

${ }^{\mathrm{c}}$ Main factors to which the metric is sensitive: hypH: hypotheses on inter-annual variability of survival of larvae and migration; Gro: anchovy growth curve; MgtStr: management strategies; effsp: effort level of Spanish fleets.
} 
Table 4: Indicators related to the other target populations and direction and significance of the effect of management scenarios on their value.

\begin{tabular}{|c|c|c|c|c|c|c|c|c|c|c|c|}
\hline \multicolumn{12}{|c|}{ Management effect on the other populations } \\
\hline & \multirow[t]{4}{*}{ Indicator } & \multirow{4}{*}{$\begin{array}{l}\text { Description, } \\
\text { computation } \\
\text { method and } \\
\text { expected effect }^{\mathrm{a}}\end{array}$} & \multirow[t]{4}{*}{ Reference } & \multicolumn{7}{|c|}{ Management effect ${ }^{\mathrm{b}}$} & \multirow[t]{4}{*}{ Sensitivity $^{\mathrm{c}}$} \\
\hline & & & & \multirow[t]{3}{*}{ 1.TAC } & 2.TAC- & 3.TAC- & 4.TAC- & \multirow[t]{3}{*}{ 5.MPA1 } & \multirow[t]{3}{*}{ 6.MPA2 } & \multirow[t]{3}{*}{ 7.MPA3 } & \\
\hline & & & & & MPA1 & MPA2 & MPA3 & & & & \\
\hline & & & & & & & & & & & \\
\hline & Final biomass & Biomass at the end & & & & & & & & & \\
\hline 01 & Sardine & of the simulation & & + & + & + & + & + & + & + & RSar \\
\hline \multicolumn{12}{|l|}{$\mathbf{0}$} \\
\hline 01 & Tuna & & & + & $+*$ & $+*$ & $+*$ & $+*$ & $+*$ & $+*$ & effp1, MgtStr \\
\hline \multicolumn{12}{|l|}{1} \\
\hline 01 & Bass Biscay & & & $-*$ & $+*$ & $+*$ & $+*$ & $+*$ & $+*$ & $+*$ & effp1, MgtStr \\
\hline \multicolumn{12}{|l|}{2} \\
\hline 01 & Bass Channel & & & $-*$ & $+*$ & $+*$ & $+*$ & $+*$ & $+*$ & $+*$ & effp1, MgtStr \\
\hline \multicolumn{12}{|l|}{3} \\
\hline & Growth rate & Trend in log & Rochet et & & & & & & & & \\
\hline 01 & Sardine & (biomass) & Trenkel, 2003 & + & + & + & + & + & + & + & RSar \\
\hline \multicolumn{12}{|l|}{4} \\
\hline 01 & Tuna & & & $+*$ & $+*$ & $+*$ & $+*$ & $+*$ & $+*$ & $+*$ & effp1 \\
\hline \multicolumn{12}{|l|}{5} \\
\hline 01 & Bass Biscay & & & $-*$ & $+*$ & $+*$ & $+*$ & $+*$ & $+*$ & $+*$ & effp1 \\
\hline \multicolumn{12}{|l|}{6} \\
\hline 01 & Bass Channel & & & $-*$ & $+*$ & $+*$ & $+*$ & $+*$ & $+*$ & $+*$ & effp1 \\
\hline 7 & & & & & & & & & & & \\
\hline
\end{tabular}




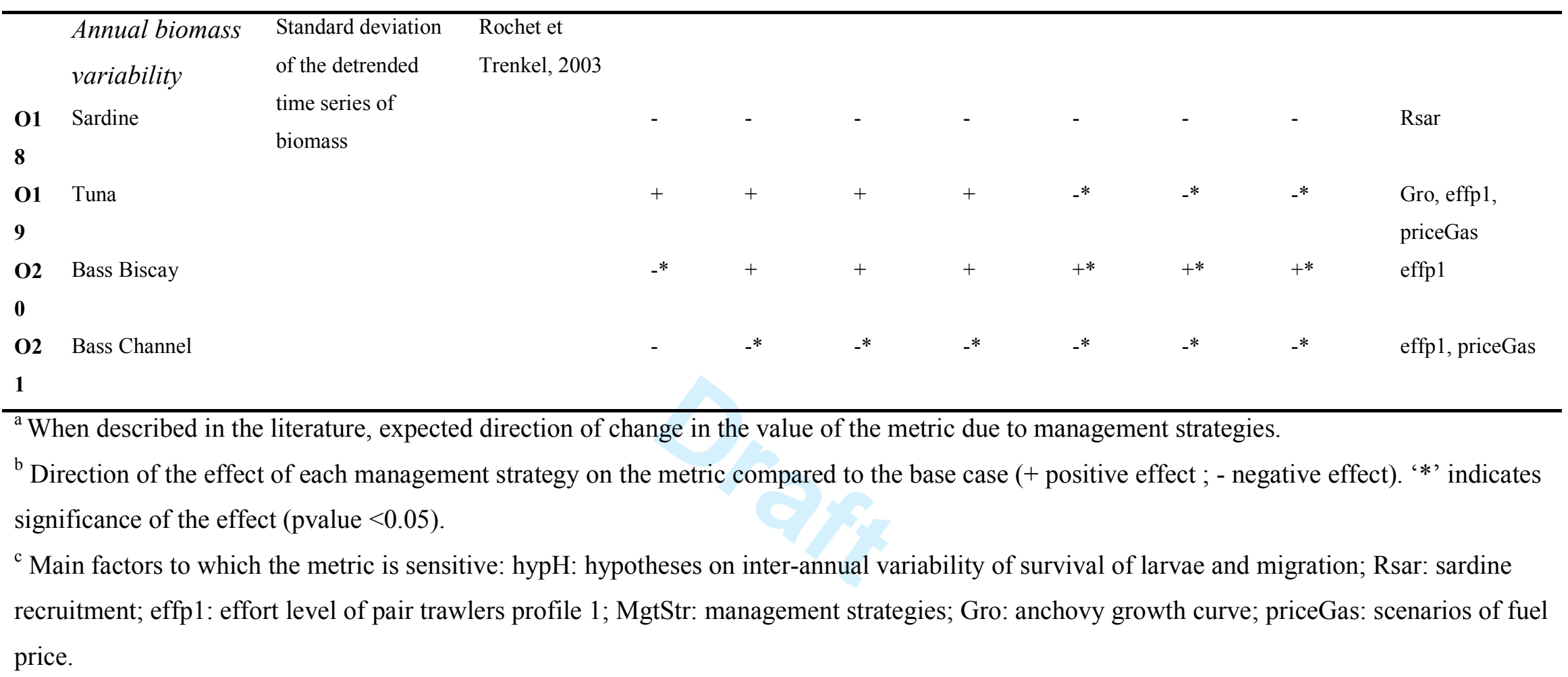


Table 5: Indicators related to fishing activity and direction and significance of the effect of management scenarios on their value.

\begin{tabular}{|c|c|c|c|c|c|c|c|c|c|c|}
\hline \multicolumn{11}{|c|}{ Management effect on fishing activity } \\
\hline & \multirow[t]{3}{*}{ Indicator } & \multirow[t]{3}{*}{ Description and/or computation method } & \multicolumn{7}{|c|}{ Management effect ${ }^{\mathrm{a}}$} & \multirow[t]{3}{*}{ Sensitivity $^{b}$} \\
\hline & & & \multirow[t]{2}{*}{ 1.TAC } & 2.TAC- & & & 5.MPA1 & 6.MPA2 & \multirow[t]{2}{*}{ 7.MPA3 } & \\
\hline & & & & MPA1 & MPA2 & MPA3 & & & & \\
\hline $\mathbf{O 2 2}$ & $\begin{array}{l}\text { Effort distribution } \\
\text { over métiers tr.p } 1^{\mathrm{c}}\end{array}$ & $\begin{array}{l}\text { Scores on } 1^{\text {st }} \text { axis of a PCA : métiers } \\
\text { targeting anchovy on the positive side }\end{array}$ & $-*$ & - & $-*$ & $-*$ & $+*$ & + & + & MgtStr \\
\hline $\mathbf{O 2 3}$ & $\begin{array}{l}\text { Effort distribution } \\
\text { over métiers tr.p1 }{ }^{\mathrm{c}}\end{array}$ & $\begin{array}{l}\text { Scores on 2nd axis of a PCA : métier } \\
\text { practice in Gironde on the negative side }\end{array}$ & $+*$ & $+*$ & $+*$ & $+*$ & $+*$ & $+*$ & $+*$ & MgtStr \\
\hline $\mathbf{O 2 4}$ & $\begin{array}{l}\text { Effort distribution } \\
\text { over métiers tr.p } 2^{c}\end{array}$ & $\begin{array}{l}\text { Scores on } 1^{\text {st }} \text { axis of a PCA : métiers } \\
\text { targeting sardine and anchovy on the } \\
\text { positive side }\end{array}$ & $-*$ & $-*$ & $-*$ & $-*$ & + & - & - & spPrice \\
\hline $\mathbf{O 2 5}$ & $\begin{array}{l}\text { Effort distribution } \\
\text { over métiers tr.p } 2^{c}\end{array}$ & $\begin{array}{l}\text { Scores on } 1^{\text {st }} \text { axis of a PCA : métiers } \\
\text { targeting sardine on the positive side and } \\
\text { anchovy on the negative }\end{array}$ & $+*$ & + & $+*$ & $+*$ & $-*$ & $+*$ & - & spPrice \\
\hline $\mathbf{O 2 6}$ & $\begin{array}{l}\text { Effort distribution } \\
\text { over métiers se.bc }{ }^{c}\end{array}$ & $\begin{array}{l}\text { Scores on } 1^{\text {st }} \text { axis of a PCA : métiers } \\
\text { targeting anchovy on the negative side }\end{array}$ & $+*$ & $+*$ & $+*$ & $+*$ & - & $+*$ & $+*$ & MgtStr \\
\hline $\mathbf{O} 27$ & $\begin{array}{l}\text { Effort distribution } \\
\text { over métiers se.br }{ }^{c}\end{array}$ & $\begin{array}{l}\text { Scores on } 2 \text { nd axis of a PCA : métiers } \\
\text { targeting anchovy on the negative side }\end{array}$ & $+*$ & $-*$ & $-*$ & $-*$ & $-*$ & $-*$ & $-*$ & effb2 \\
\hline $\mathbf{O} 28$ & $\begin{array}{l}\text { Anchovy } \\
\text { international }\end{array}$ & Landings cumulated over the simulation & + & - & $-*$ & - & $-*$ & $-*$ & $-*$ & $\begin{array}{l}\text { Paita, } \\
\text { MgtStr }\end{array}$ \\
\hline & landings & & & & & & & & & \\
\hline $\mathbf{O 2 9}$ & $\begin{array}{l}\text { Anchovy landings of } \\
\text { French fleets }\end{array}$ & Landings cumulated over the simulation & $-*$ & $-*$ & $-*$ & $-*$ & $-*$ & $-*$ & $-*$ & Paita, effsp \\
\hline $\mathbf{O 3 0}$ & Anchovy landings of & Landings cumulated over the simulation & $+*$ & $+*$ & $+*$ & $+*$ & - & + & - & Paita, \\
\hline
\end{tabular}


Spanish fleets

${ }^{a}$ Direction of the effect of each management strategy on the metric compared to the base case (+ positive effect ; - negative effect). ' ${ }^{*}$ ' indicates significance of the effect (pvalue $<0.05$ ).

${ }^{\mathrm{b}}$ Main factors to which the metric is sensitive: MgtStr: management strategies; spPrice: flexibility coefficients of price equations for the species; effp1: effort level of pair trawlers profile 1; Gro: coefficients of anchovy growth curve; priceGas: scenarios of fuel price; effb2: effort level of purse seiners from Brittany; païta: level of live bait catches of anchovy by Spanish fleets for tuna fishing; effsp: effort level of Spanish fleets. ${ }^{c}$

Greenstreet et al. (2009) 
Table 6: Indicators related to revenues of the fishing industry and direction and significance of the effect of management scenarios on their value.

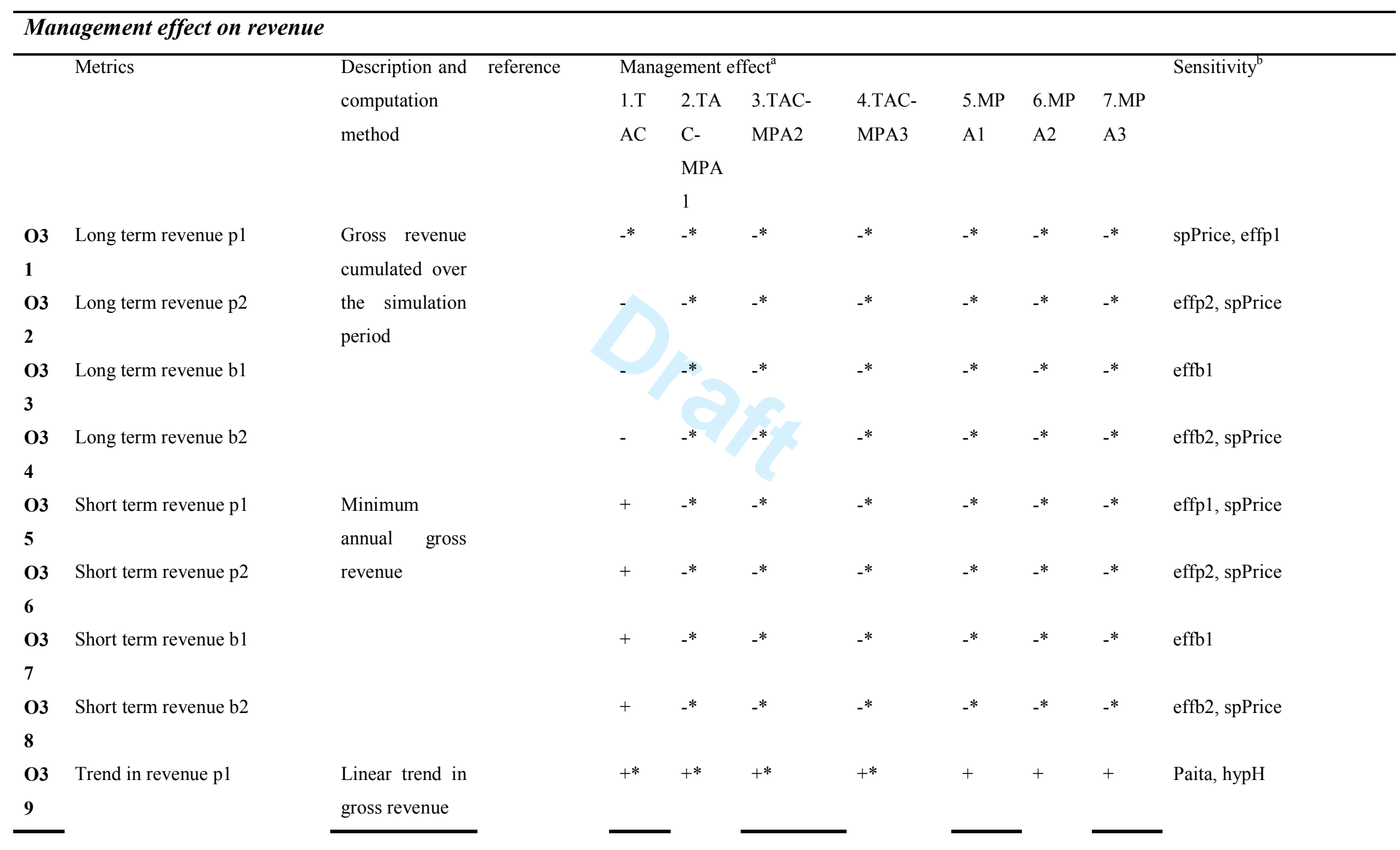




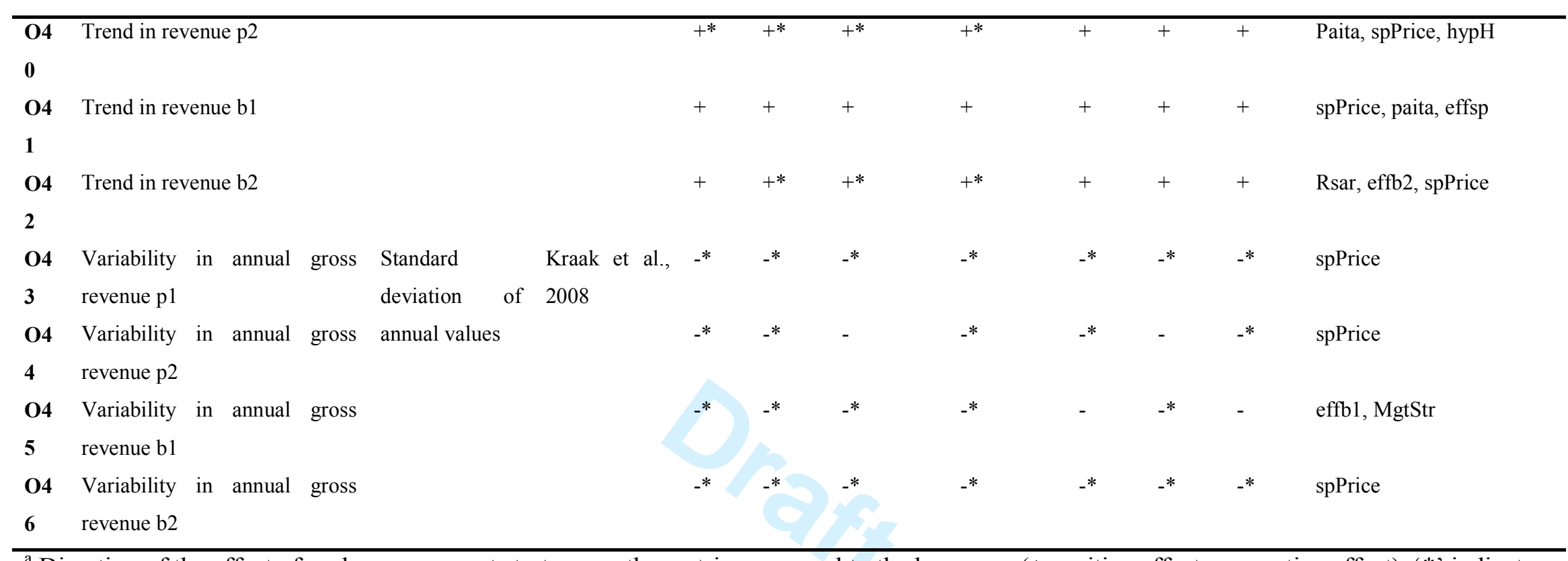

${ }^{a}$ Direction of the effect of each management strategy on the metric compared to the base case (+ positive effect ; - negative effect). '*' indicates significance of the effect (pvalue $<0.05$ ).

${ }^{\mathrm{b}}$ Main factors to which the metric is sensitive $\mathrm{p} 1$ : pair trawlers profile 1; $\mathrm{p} 2$ : pair trawlers profile 2; b1:purse seiners from the Basque Country; b2:purse seiners from Brittany ; spPrice: flexibility coefficients of species price equations ; effp1: effort level of pair trawlers profil 1; effp2: effort level of pair trawlers profil 2; païta: level of live bait catches of anchovy by Spanish fleets for tuna fishing; hypH: hypotheses on interannual variability of survival of larvae and migration; effsp: effort level of Spanish fleets; Rsar: sardine recruitment; effb2: effort level of purse seiners from Brittany; MgtStr: management strategies. 
Table 7: Indicators related to the price of anchovy and direction and significance of the effect of management scenarios on their value.

\begin{tabular}{|c|c|c|c|c|c|c|c|c|c|c|}
\hline \multicolumn{11}{|c|}{ Management effect on anchovy price } \\
\hline & \multirow[t]{3}{*}{ Metrics } & \multirow[t]{3}{*}{ Expected effect ${ }^{\mathrm{a}}$} & \multicolumn{7}{|c|}{ Management effect ${ }^{b}$} & \multirow[t]{3}{*}{ Sensitivity $^{\mathrm{c}}$} \\
\hline & & & \multirow[t]{2}{*}{ 1.TAC } & 2.TAC- & 3.TAC- & 4.TAC- & 5.MPA1 & 6.MPA2 & 7.MPA3 & \\
\hline & & & & MPA1 & MPA2 & MPA3 & & & & \\
\hline 047 & $\begin{array}{l}\text { Average annual price anchovy } \\
\text { category } 10 \text { (large) }\end{array}$ & $\begin{array}{l}\text { Prices are expected to rise when } \\
\text { MPA are enforced }\end{array}$ & $+*$ & $+*$ & $+*$ & $+*$ & $+^{*}$ & $+*$ & $+*$ & spPrice \\
\hline 048 & $\begin{array}{l}\text { Average annual price anchovy } \\
\text { category } 40 \text { (small) }\end{array}$ & & $+*$ & $+*$ & $+*$ & $+^{*}$ & $+^{*}$ & $+*$ & $+*$ & paita \\
\hline 049 & $\begin{array}{l}\text { Variability of average annual } \\
\text { price anchovy cat } 10\end{array}$ & & $+^{*}$ & $+*$ & $+*$ & $+*$ & $\mathrm{a}$ & + & + & spPrice \\
\hline $\mathbf{0 5 0}$ & $\begin{array}{l}\text { Variability of average annual } \\
\text { price anchovy cat } 40\end{array}$ & & + & -* & - & $-*$ & - & + & - & hypH \\
\hline
\end{tabular}

\footnotetext{
${ }^{a}$ When described in the literature, expected direction of change in the value of the metric due to management strategies.

${ }^{b}$ Direction of the effect of each management strategy on the metric compared to the base case ( + positive effect ; - negative effect). '*' indicates significance of the effect (pvalue $<0.05$ ).

${ }^{\mathrm{c}}$ Main factors to which the metric is sensitive: spPrice: flexibility coefficients of species price equations ; païta: level of live bait catches of anchovy by Spanish fleets for tuna fishing; hypH: hypotheses on inter-annual variability of survival of larvae and migration.
} 
Table 8: Indicators related to fuel expenses for the French fleets and direction and significance of the effect of management scenarios on their value.

\begin{tabular}{|c|c|c|c|c|c|c|c|c|c|c|c|}
\hline \multicolumn{12}{|c|}{ Management effect on Fuel costs } \\
\hline & \multirow[t]{3}{*}{ Indicator } & \multirow[t]{3}{*}{ reference } & \multirow{3}{*}{$\begin{array}{l}\text { Description and } \\
\text { computation method }\end{array}$} & \multicolumn{7}{|c|}{ Management effect ${ }^{\mathrm{a}}$} & \multirow[t]{3}{*}{ Sensitivity $^{b}$} \\
\hline & & & & 1.TAC & 2.TAC- & 3.TAC- & 4.TAC- & 5.MPA1 & 6.MPA2 & 7.MPA3 & \\
\hline & & & & & MPA1 & MPA2 & MPA3 & & & & \\
\hline 051 & Fuel cost $\mathrm{fh}^{-1} \mathrm{p} 1$ & & & $-*$ & - & $-*$ & - & $+*$ & + & $+*$ & PriceGas \\
\hline 052 & Fuel cost $\mathrm{fh}^{-1} \mathrm{p} 2$ & & & $-*$ & + & - & & + & + & + & PriceGas \\
\hline $\mathbf{0 5 3}$ & Fuel cost $\mathrm{fh}^{-1} \mathrm{~b} 1$ & & & $+*$ & $+*$ & $+*$ & - & - & $+*$ & - & effb1 \\
\hline 054 & Fuel cost $\mathrm{fh}^{-1} \mathrm{~b} 2$ & & & + & + & + & + & + & + & + & PriceGas \\
\hline 055 & Trends in fuel costs $p 1$ & Bastardie et & Linear trend in fuel costs & + & + & + & + & & & & PriceGas \\
\hline 056 & Trends in fuel costs $\mathrm{p} 2$ & al., 2010 & & + & + & + & + & & & & PriceGas \\
\hline $\mathbf{0 5 7}$ & Trends in fuel costs b1 & & & $+*$ & $+*$ & $+*$ & + & + & + & + & PriceGas \\
\hline 058 & Trends in fuel costs b2 & & & - & - & - & - & - & - & - & PriceGas \\
\hline 059 & Fuel dependency p1 & Le Corre et & Fuel costs / revenu & + & - & - & - & & & & spPrice \\
\hline 060 & Fuel dependency p2 & al., 2010 & & - & - & - & - & - & - & - & spPrice \\
\hline 061 & Fuel dependency b1 & & & $+*$ & $+^{*}$ & $+^{*}$ & + & - & $+*$ & $-*$ & effb1 \\
\hline 062 & Fuel dependency b2 & & & + & - & - & - & - & - & - & spPrice \\
\hline 063 & Trend in fuel dependency $\mathrm{p} 1$ & & $\begin{array}{l}\text { Linear trend in fuel } \\
\text { dependency }\end{array}$ & - & - & - & - & + & + & + & $\begin{array}{l}\text { PriceGas, } \\
\text { spPrice }\end{array}$ \\
\hline 064 & Trend in fuel dependency $\mathrm{p} 2$ & & & - & - & - & - & - & - & - & PriceGas \\
\hline 065 & Trend in fuel dependency b1 & & & + & + & + & + & + & + & $+*$ & PriceGas \\
\hline 066 & Trend in fuel dependency b2 & & & + & + & + & + & & & & PriceGas \\
\hline
\end{tabular}

\footnotetext{
${ }^{\mathrm{a}}$ Direction of the effect of each management strategy on the metric compared to the base case (+ positive effect ; - negative effect). ' $*$ ' indicates
} significance of the effect (pvalue $<0.05$ ). 


\footnotetext{
${ }^{b}$ Main factors to which the metric is sensitive: p1: pair trawlers profile 1; p2: pair trawlers profile 2; b1:purse seiners from the Basque Country; b2:purse seiners from Brittany ; PriceGas: scenarios of fuel price evolution; spPrice: flexibility coefficients of species price equations ; effb1: effort level of purse seiners from the Basque Country.
} 
Table 9: Parameters to which performance metrics are the most sensitive according to the results of the sensitivity analysis ( $>10 \%$ of explained variability).

\begin{tabular}{ll}
\hline & Major source of variability \\
\hline P1 & Hyp. H1/H2, management, païta \\
P2 & Païta, management, effort of Spanish fleet \\
P3 & Païta, management, effort of pair trawler fleet profil 1 \\
P4 & Hyp. H1/H2, païta \\
P5 & Management, effort of pair trawler fleet profil 1, Hyp. \\
& H1/H2 \\
P6 & Hyp. H1/H2 \\
\hline
\end{tabular}




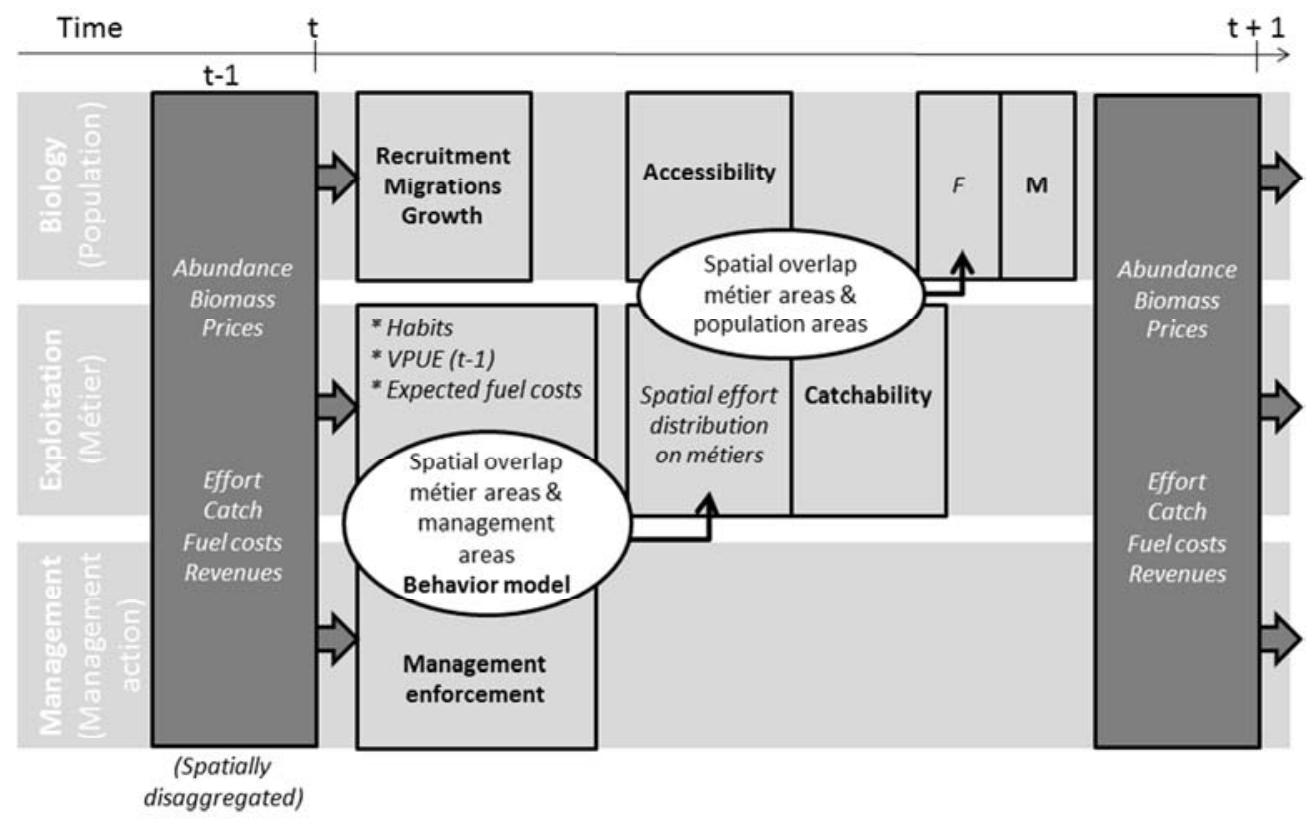

Figure 1: Graphical summary of the ISIS-Fish model of the pelagic fishery in the Bay of Biscay. The chart represents the events simulated by each sub-model (biology, exploitation and management) at each time step ( $t$, month) and the connections between them which result in the computation of the fishing mortality $(F)$. Bolded words represent processes; italic is used to indicate state variables dynamically computed. $F$ : Fishing mortality; M: natural mortality; VPUE: Value landed per Unit of Effort. $254 \times 190 m m$ (96 x 96 DPI) 

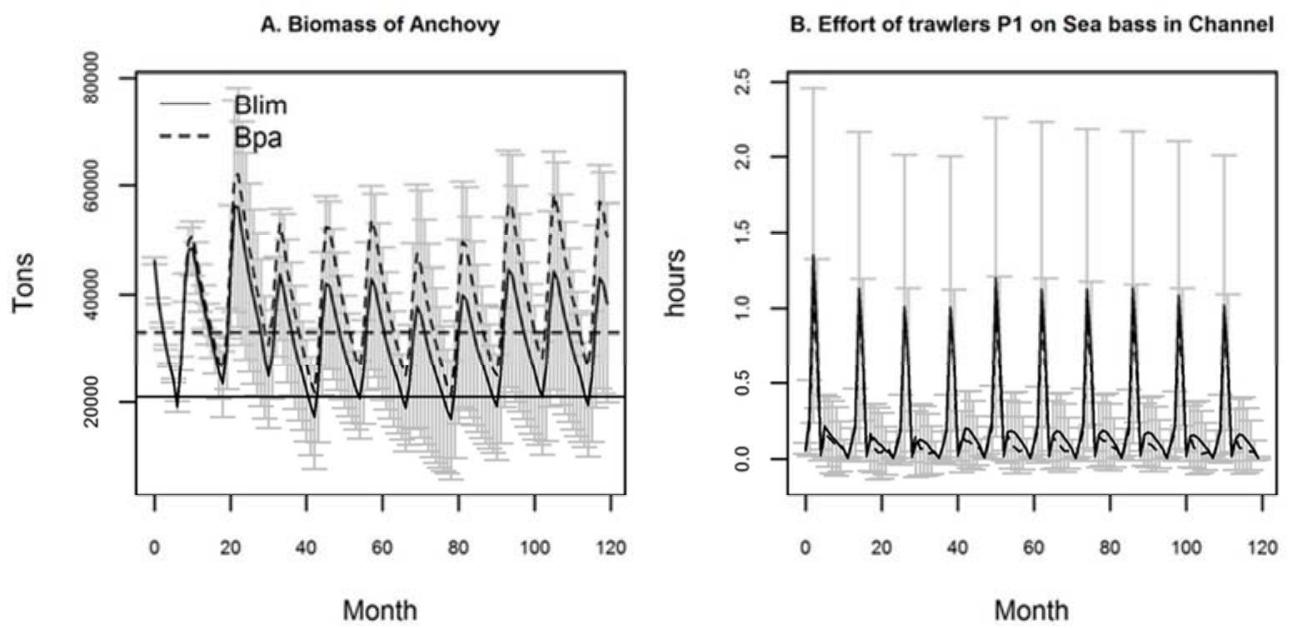

C. Trawlers P1 catch of Anchovy in Gironde
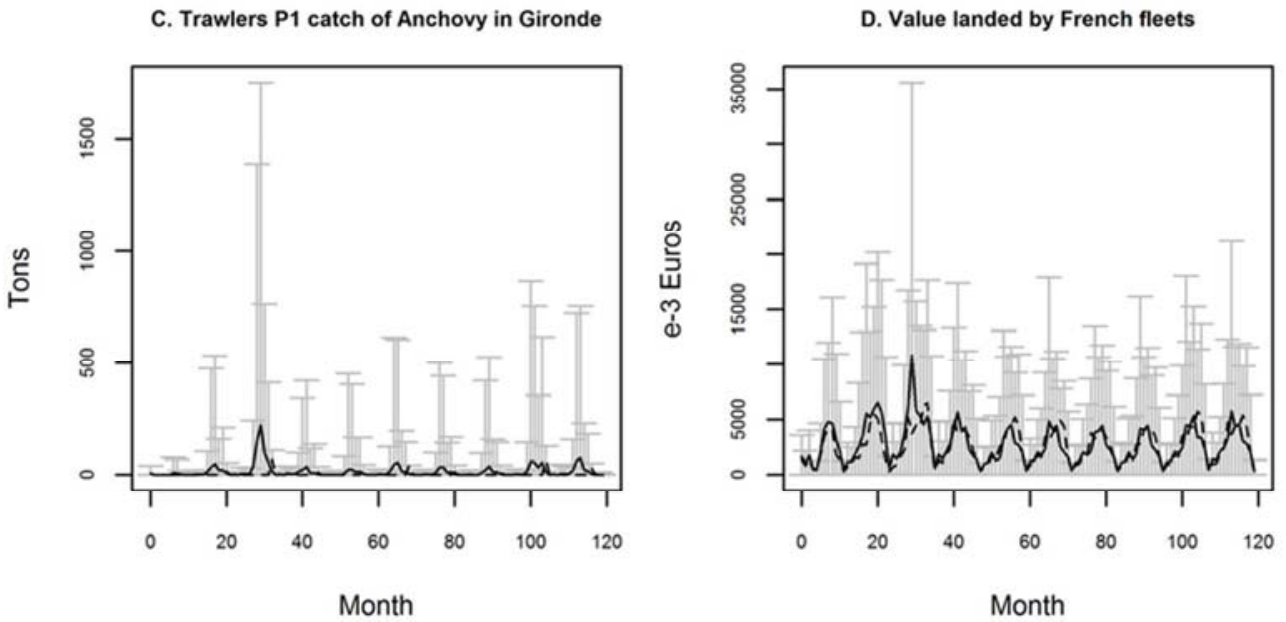

Figure 2: Examples of time series of outputs produced by the ISIS-Fish model of the pelagic fishery in the Bay of Biscay. The average time series obtained in the base case simulation is plotted (continuous bold line) together with $95 \%$ confidence intervals derived from the simulation design. The dash line represents the average time series obtained in simulations with management strategy 2 (TAC +MPA 1 ). A. Monthly biomass of anchovy, with reference levels Blim (biomass limit) and Bpa (precautionary biomass). B. Monthly effort of trawlers profil 1 on métiers targeting sea bass in the Channel. C. Monthly catches of anchovy by trawlers profil 1 in area Gironde. D. Monthly revenues generated by French fleets. $139 \times 139 \mathrm{~mm}(150 \times 150 \mathrm{DPI})$ 


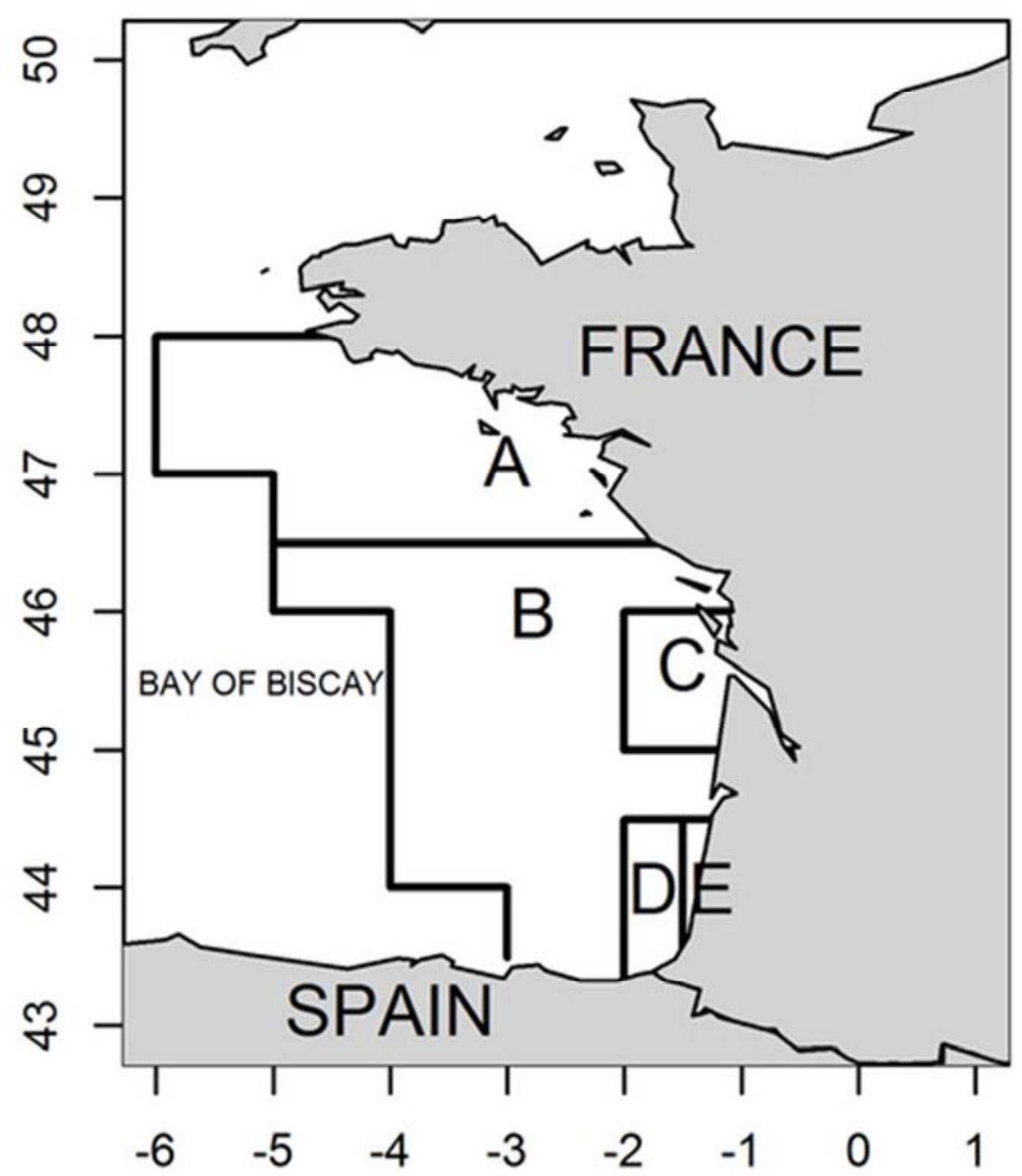

Figure 3: Map of biological and management areas for anchovy in the Bay of Biscay. A North, B. Rochebonne, C. Gironde, D. Landes off, E. Landes coastal. $79 \times 91 \mathrm{~mm}(150 \times 150 \mathrm{DPI})$ 


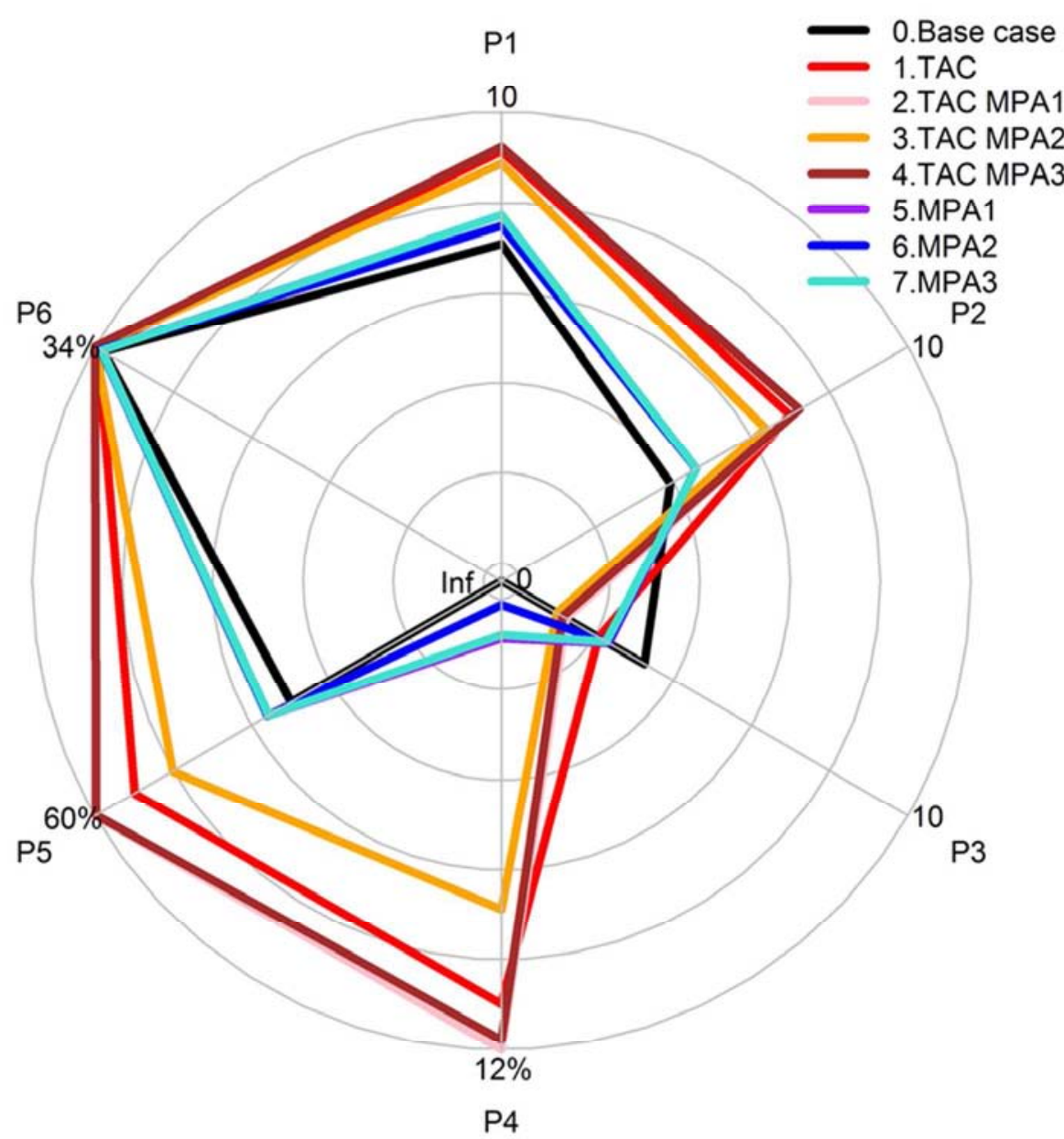

Figure 4: Radar plot of average value obtained in simulation for the performance metrics in each management scenarios. Performance metrics are ordered on the graph according to the dimension to which they referred: biological objectives on the right and economic objectives on the left. Metrics are scaled so that the more on the edge the better. The scale goes from 0 to 10 (simulation duration) for P1 to P3, from 0 to the maximum value observed in simulation for P3. We plot the inverse of P5 and P6 so that the values range from Infinity to the lowest value observed in simulation. P1: no. years with biomass higher than Blim $\in[0 ; 10] ;$ P2: no. years of open closure $\in[0 ; 10] ; \mathrm{P} 3$ : no. years with anchovy catch $>7000 t \in[0, \max =3.47]$; P4: trend in biomass time series $\in[\min ; \max ]$; P5: 1/inter-annual variation in anchovy landings $\epsilon$ [Infinity;max]; P6: 1/variability of age structure $\in$ [Infinity;min]. "min" and "max" stands respectively for minimum and maximum obtained in simulations. $139 \times 139 \mathrm{~mm}(150 \times 150 \mathrm{DPI})$ 
P1: Number of years with B>Blim

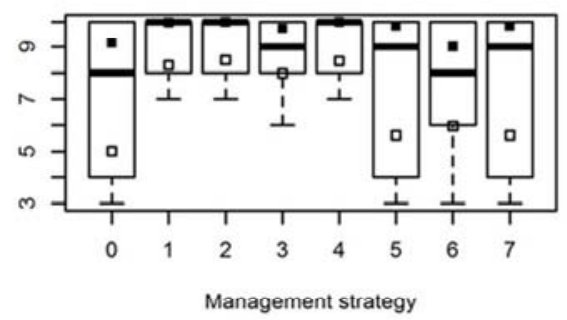

P3: Number of years with $>7000 t$ anchovy catch

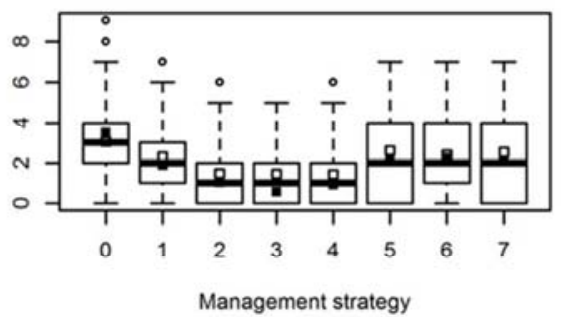

P5: Variability of anchovy landings \%

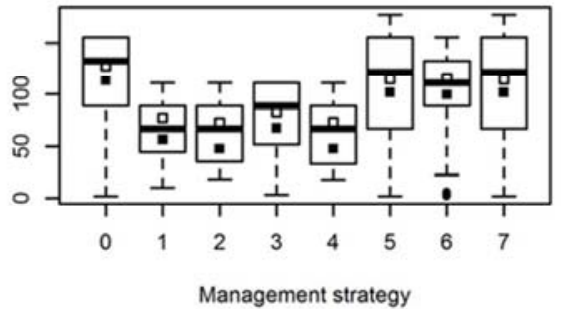

P2: Number of years of opening

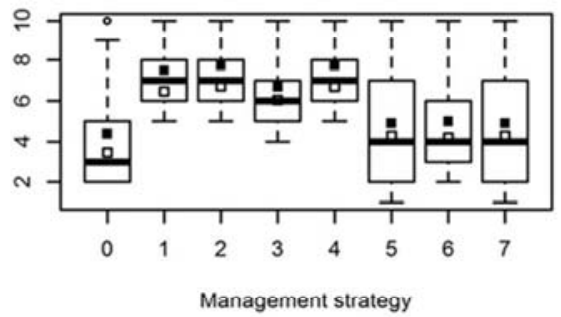

P4: Anchovy population growth rate \%

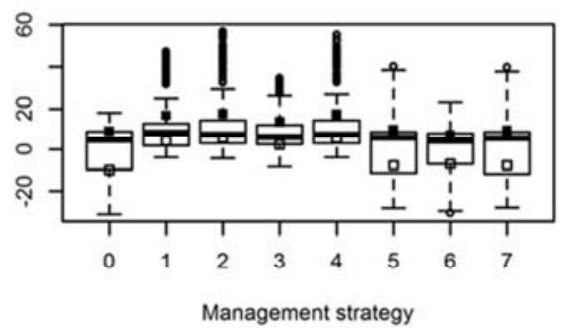

P6: Variability of age structure \%

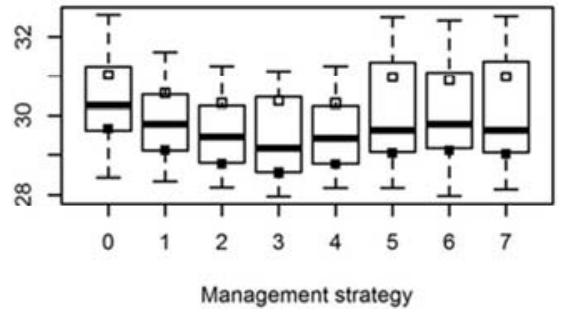

Figure 5: Boxplots of the values of the six performance metrics depending on management strategies ( $x$ axis) (boxes represent the median and first and third quartile). The solid square represents the average value obtained in simulations with constant natural mortality and migration scheme, while the open square is the average value in simulations including inter-annual variability in these processes.

Figure 6: Sensitivity indices (16 highest) corresponding to each uncertainty source and management scenario for metric P4: Anchovy population growth rate and P5: Variability of anchovy landings. Sensitivity indices relating to management are in black. ":" represents interaction between two factors. Please report to

Table 1 for the meaning of the abbreviations.

$$
139 \times 139 \mathrm{~mm}(150 \times 150 \mathrm{DPI})
$$



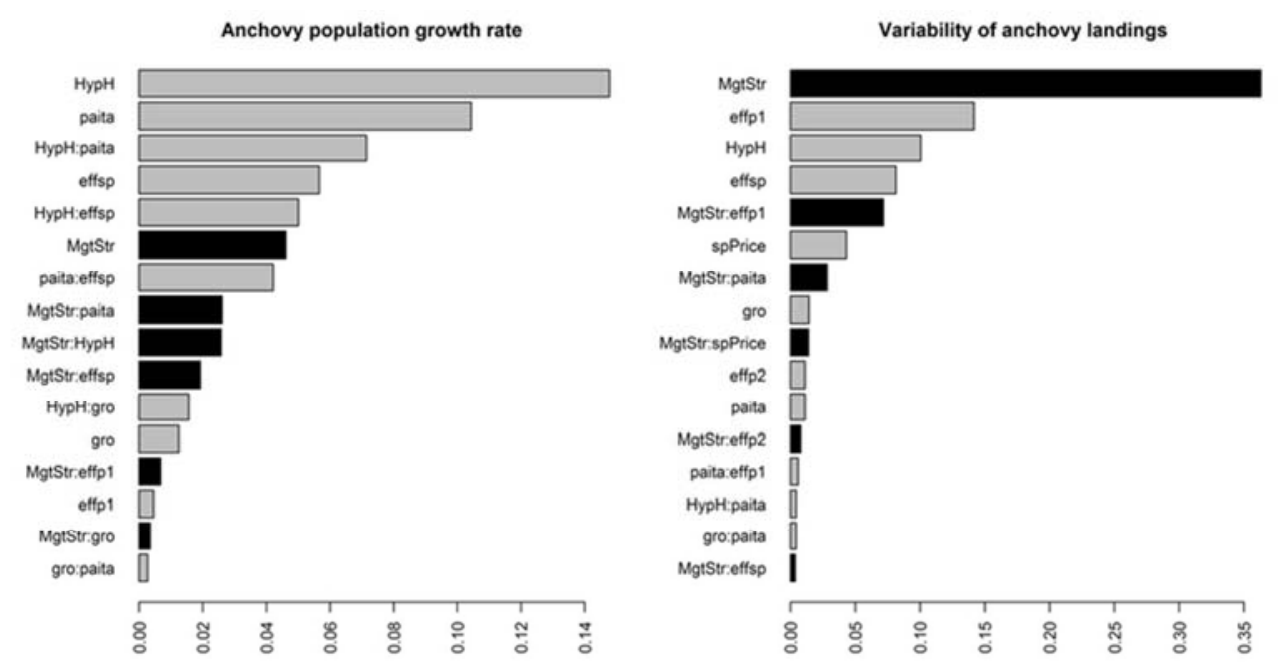

Figure 6: Sensitivity indices (16 highest) corresponding to each uncertainty source and management scenario for metric P4: Anchovy population growth rate and P5: Variability of anchovy landings. Sensitivity indices relating to management are in black. ":" represents interaction between two factors. Please report to Table 1 for the meaning of the abbreviations. $139 \times 69 \mathrm{~mm}(150 \times 150 \mathrm{DPI})$ 

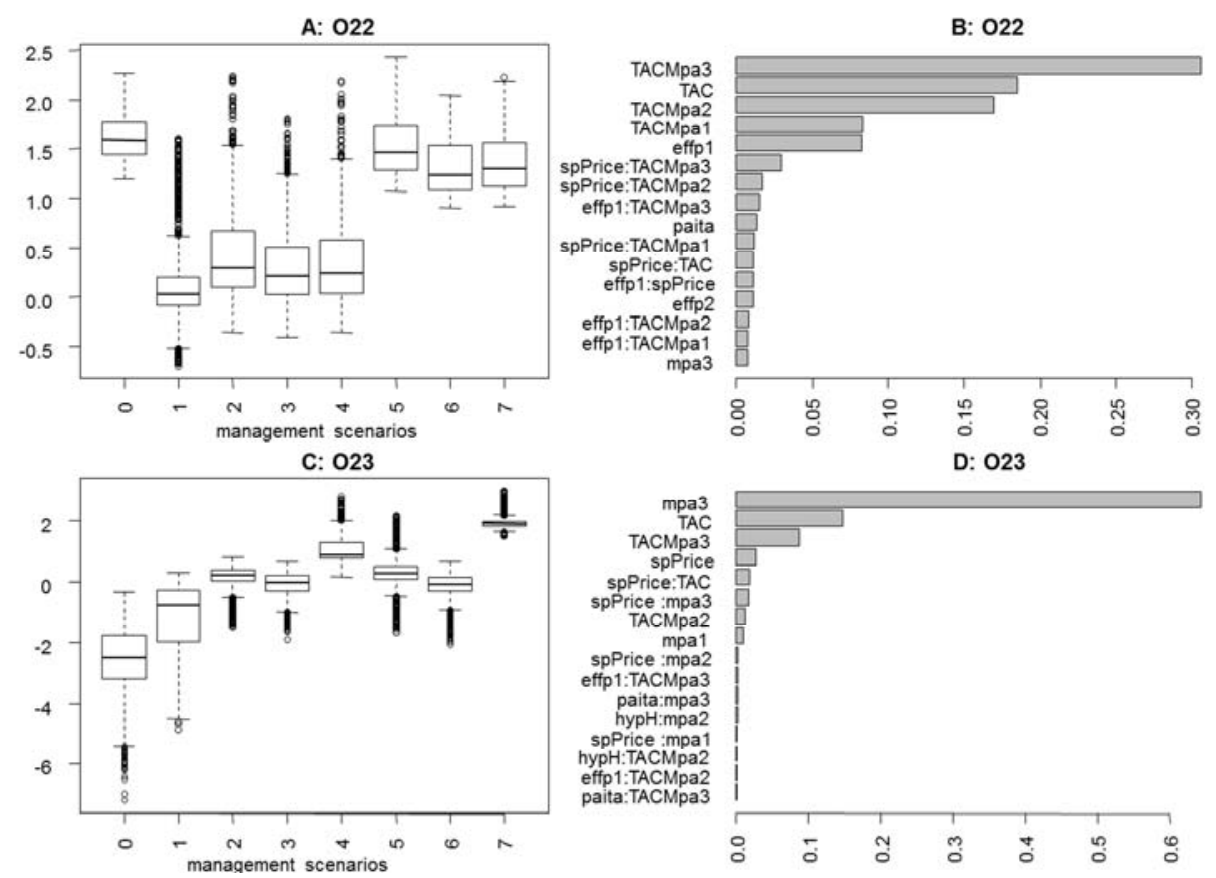

Figure 7: Effect of management scenarios on the allocation of effort of trawlers profile 1 on métiers, metrics $\mathrm{O} 22$ (top) and $\mathrm{O} 23$ (bottom). A and C: Simulated values of the metric depending on management scenario ( $x$ axis) (boxes represent the median and first and third quartile). B and D:. Sensitivity indices (16 highest) of the metric corresponding to each uncertainty source and management scenario and computed based on variance decomposition; ":" represents interaction between two factors. Please report to Table 1 for the meaning of the abbreviations. $381 \times 254 \mathrm{~mm}(96 \times 96 \mathrm{DPI})$ 